Portland State University

PDXScholar

7-30-1971

\title{
The Effectiveness of Environmental Control in Modifying Problem Behaviors in Mother-Child Interaction
}

Thomas Whalen Hamilton

Portland State University

Follow this and additional works at: https://pdxscholar.library.pdx.edu/open_access_etds

Part of the Applied Behavior Analysis Commons, Child Psychology Commons, and the Social

Psychology and Interaction Commons

Let us know how access to this document benefits you.

\section{Recommended Citation}

Hamilton, Thomas Whalen, "The Effectiveness of Environmental Control in Modifying Problem Behaviors in Mother-Child Interaction" (1971). Dissertations and Theses. Paper 1403.

https://doi.org/10.15760/etd.1402

This Thesis is brought to you for free and open access. It has been accepted for inclusion in Dissertations and Theses by an authorized administrator of PDXScholar. Please contact us if we can make this document more accessible: pdxscholar@pdx.edu. 
AN ABSTRACT OF THE THESIS OF Thomas Whalen Hamilton for the Master of Science in Psychology presented July 30, 1971.

Title: The Effectiveness of Environmental Control in Mod1fying Problem Behaviors in Nother-Child Interaction. APPROVED BY MEMBERS OF THE THESIS COIMITTEE:
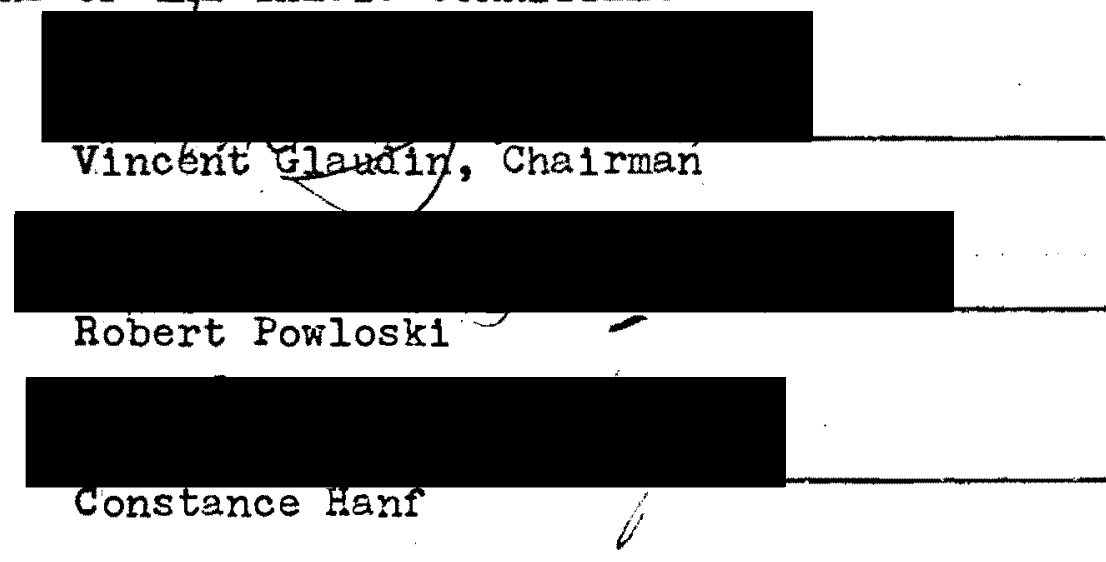

An experiment was designed to test the effectiveness of using standard laboratory environments in producing a broad class of problem behaviors which defined Mother-Child ( $\underline{\underline{K}}-\underline{C})$ interaction difficulties. The effects of four environments, free-time $(X)$, child's game and rules (B), mother's game and rules (C), and clean-up ( $Z$ ), on the frequency of elght criteria behaviors were tested on $12 \underline{M}-\underline{C}$ palrs over three days of baseline data collection. It was predicted that the frequency of problem behaviors would decrease as a function of environment $(X)$ and increase as a function of environments (B), (C), and (Z). A two factor repeated measures design was used for the baseline data analyses. Analysis of the data confirmed the experinental predictions. It was con- 
cluded that the use of standard Jaboratory environments was effective in increasing the frequency of problem behaviors which define $M-C$ interaction difficulties. These conclusjons were discussed in view of the contribution made by the use of enviromental control in the application of behavior modification techniques to $\underline{M}-\underline{C}$ interaction difficulties. 
THE EBFECTYVENGSS CF EIVIBONHENTAL

CONTHOL IN WODTFING FROBI,EN BEFAVIORS IN HOTHEF-CHID INIBPACIION

by

Thomas Whalen Hamjiton

Presented to the Iepartment of Psycholosy in partidol. rulfilinent of the requirements for the destee of

$$
\text { Mastor of Aris }
$$

Portland State University

1971 
TO THE OFICE OF GRADUATE STUDIES:

The members of the Comrittee approve the thesis of Thomas Whalen Hamilton presented July 27, 1971.

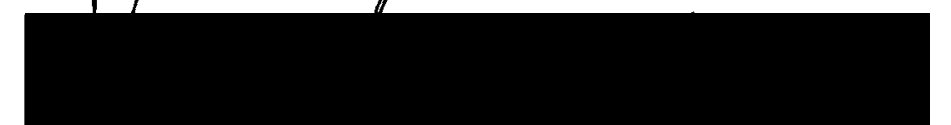

Vincent Glabian, Chairman

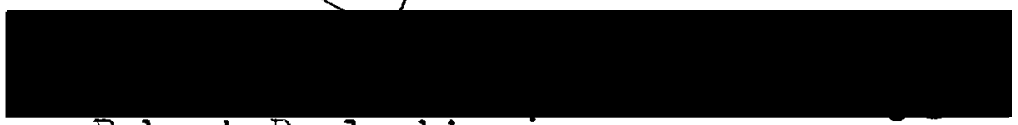

Robert Powloski

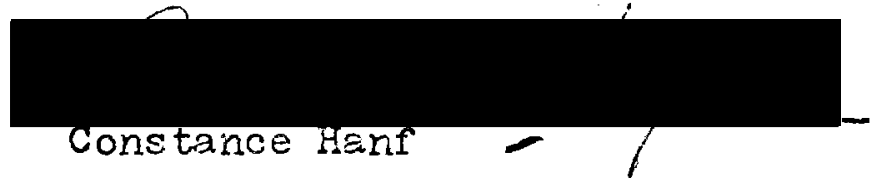

APPROVED :

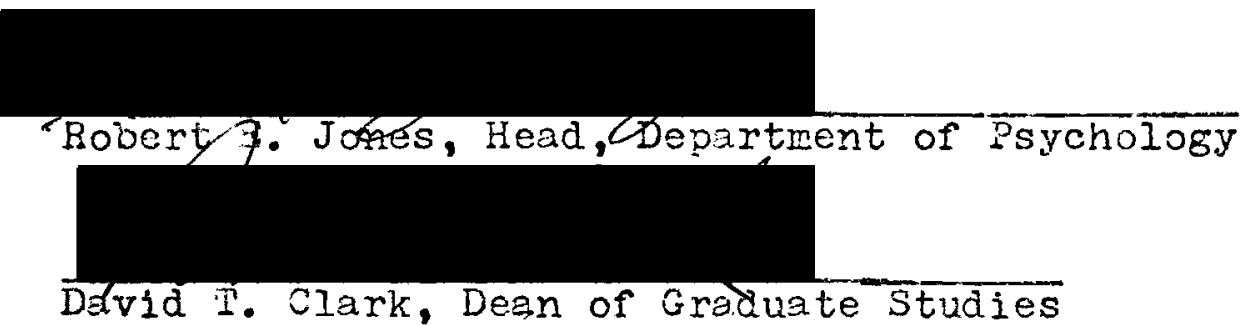

July 30,1971 


\section{ACKNOHLWDGMENS}

I am especially indebted to $\mathrm{Ix}$. Constance Hanf whose lons hours of personal interest, energy, and professional expertise over the past two years have made this endeavor a rewarding learning experience. The ever present encouragement, consultation, and patience of Dr. Robert Powloski and Dr. Barbara Weiner was appreciated and greatly facilitated the developmental stages of the author. The serious questions, evaluations, and critiques presented by Dr. Vincent Glaudin have greatly improved the quality of this payer and the skills of the author.

The countless hours of tycing, statistical computation, and proof reading conductea by my wife Linda were secondary to her cheracteristics of humor, encouragement, and confidence in the corpletion of this work. 
TABLE OF CONDENSS

Page

ACKNOHLEDGHENT . . . . . . . . . . . . . . III IIST OF TABLES . . . . . . . . . . . . . . . VI IMTROLUCTION ................... 1

Theoretical Considerations . . . . . . . 4

Genexal Applications . . . . . . . . . 7

Applications to Chije Behavior . . . . . . 11

Training parents in a meraplst Bole ..... 18

in the home............. . . 19

in the Jaboratory ........... 23

HANE'S PROCEDURE . . . . . . . . . . . . . 28

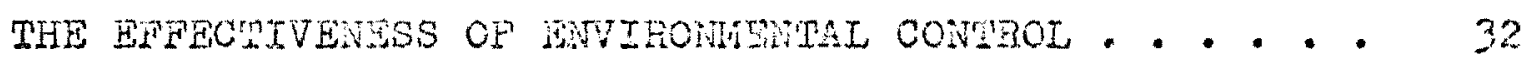

Statement of the froblem . . . . . . . . 32 METHOI . . . . . . . . . . . . . . . . 34

subjecis . . . . . . . . . . . 34

Equipment and Iaboratory setting . . . . . 34

Specjfic Frocedures . . . . . . . . . 35

Initial Intervier . . . . . . . . . 35

Exaline Leta cojlection......... . . 36

heliabizity ............ . . 40

EESULSS . . . . . . . . . . . . 42

DISCUSSIOL . . . . . . . . . . . . . $6 \delta$

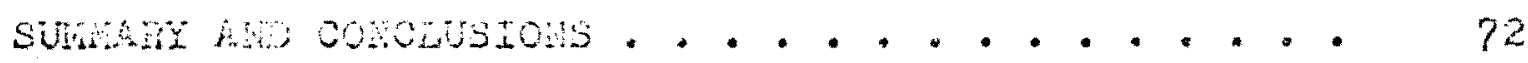

EIERCOLAR . . . . . . . . . . . . . . 74

APEMLIX A. . . . . . . . . . . . . . 80 
TABLE OF CONTENTS

Page

APPENDIX B . . . . . . . . . . . . 89

APPENDIX C . . . . . . . . . . . . . . 91

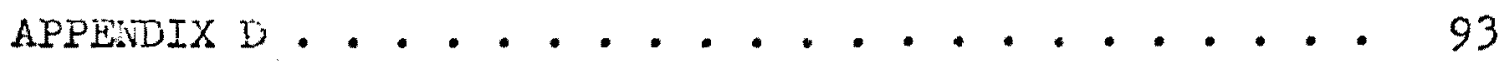




\section{IIST OF TABLES}

Table

Fage

I. AB Summary of Observed Data, Analysis of Variance, and Test on Means Us Ing Newman-KeuIs procedure on Gives up Control ....... 43

II. $A B$ Summary of Observed Lata, Analysis of Varlance, and rest on lieans Usjung Newman-Keuls Procedure on Independent Play ...... 45

III. AB Sumnary of Observed Data, Analysis of Varlance, and Test on Means Usins Newman-Keuls Procedure on Interaction . . . . . . .

IV. AB Summary of Observed Data, Analysis of Variance, and Test on Means Using Newman-Keuls Procedure on Follows in $\underline{C}^{\prime} \mathrm{s}$ Play . . . . .

v. AB Sumary of Observeci Lata and Análysis of Variance on Revards.......... 52

VI. AB Summary of Observed Lata, Analysis of Varlance, and Test on Means Using Newran-Kouls Procedure on Cormands . . . . . . . . .

VII. AB Sunmary of Observed Data, Analysis of Varlance, and Test on Means Using Newman-Keuls Procedure on Complies . . . . . . . 55

VIII. AB Summary of Observed Data, Analysis of Varlance, and Test on lieans Using Newman-Keuls Procedure on Asks questions . . . . . 58

IX. Comparison of the Mean Frequencies of the Eight Criteria Behaviors between Groups $B_{1}$

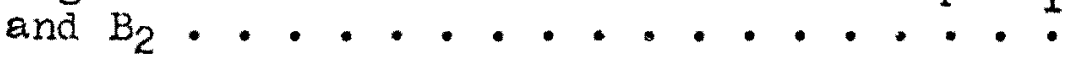

x. Comparisors of the liean Frequencies of the Eight Criteria Behaviors between Groups $c_{1}$ and $\mathrm{C}_{2}$..............

XI. Comparison of the Hean Frequencies of the Fight Criteria Benaviors botween Groups $z_{1}$ anà $Z_{\iota_{2}} \cdot$. . . . . . . . . . . . 


\section{INTROLUCIION}

In recent years the development of a body of literature that concentrates on the modification of huran social behaviors supports the contention that the employment of operant techniques in Behavior Therapy has a wide range of effective applications. The history of the operational analysis of human behavior, the operant paradigm, and the extension of this paradigm to the modification of huran behaviors evolved from the development of "logical positivism" in philosophy dating back to Immanual Kant (1781) and Behavioristics in psychology. A detailed review of this historical development is contained in Appendix $A$.

In psychology, behavior principles find theix origin in the "School of Behaviorism" founded by John B. Watson in 1913 with a paper entitled Psychology as a Behaviorist Vievs It. Watson could not tolerate the requirement of the chicago School to translate positively observed behavior into the vague terms of consciousness. He found it more direct, irteresting, and positive to study behavior for its om sake. Watson was the agent of a reaction between consciolisness throush introspection and objectivity in psycholocy, the result of which was observation of operations in behavior. Throush him, Behaviorisn becene a psychology of stimulus and response as he proceeded to transiate mentalistio conopts 
like imagery, feeling and association into such behavioral terms as vocimotor behavior, glandular activity, and Pavlovian conditioned reflexes respectively. Those who followed Watson in the development of behavior principles vere Holt, Tolman, Lashley, Weiss, Skinner, and Hull.

Burrhus Frederic Skinner made contact with "logical positivisu" and Behaviorism while pursuing a literary career at Greenwich Village in 1927. He became acquainted with Bertrand fiussell's articles in the Dial magazine on the episterology of John B. Watson's Behaviorism. Russell was extrapolating the principles of an objective formulation of behavior to the problem of knowledge. Skinner was interested in huiran behavior but trie literary method had falled him so he turned to science and entered graduate studies in psychology at Harvard. In his search for order in behavior, Russell and Watson had provided hid no glimpse of experimenta]. nethod but Pavlov had: "control the environment and you vill see order In behavior." (Skinner 1952) Thus began Skinner's worih on "operant behavior" a term he first used in the Behavior of Organisms (1938). He vent directly to the observation of operations in behavior for his data in formulating a system of behavior. In studyins behavior, he made a strons point of observing only the correlation between stimulus and response. The advantage of tinls approach was seen as obtalning a systen of behavior which has a struoture determined by the subjeot . aatter 1tself. Shinner describes two types of behavior, 
"respondent" and "operant". Nuch work had been done on respondent behavior since Pavlov's time and it came to be assumed by many writers that all behavior would be accounted for by properly identifying the appropriate antecedent eliciting stimuli. But skinner objected to this assunption saying that there is a large amount of behavior that does not seem to be 'elicited', since one can observe no correlation between antecedent events and corresponding responses. To force all behavior into the stimulus-response formula has delayed the treatment of this 'other' behavior. Addressing himself to the problem of this other (operant) behavior, skinner said that events in behavior can occur without any observable antecedent events (unconditioned stimuli) and thus the behavior is emitted spontaneously rather than elicited. This type of spontaneous behavior he called operant, which refers to a subsequent event, a consequence.

In describing what he meant by operant behavior, Skinner established two laws: 1) The Law of Conditioning of type $R$ : If the occurrence of an operant is followed by the presentation of a reinforcing stimulus, the strensth (frequency) of the operant is increased; 2) The Law of Extinction of type $R$ : If the occurrence of an pperant already strengthened through conditioning is not followed by the reinforcirs stimulus, the strenstin (frequency) is decreased. (Skinner 1938) The interaction between an orgenise and the entronment des cribes operant behavior, behavior that is affected by 1 ts 
environmental consequences.

In general, the technique of operant cond1tionj.ng consists of three stages: 1) measuring the operant level or baseline of the response(s) to be observed; 2) presenting a potential reinforcer following the occurrence of the response until an increase in strength (frequency) is demonstrated; 3) withholding the reinforcer and allowing the response to extinguish. The response is then reconditioned to increase the experimenter's confidence that he has isolated the relevant variables. Environmental control meant to skinner the manipulation of response-reinforcement contingencies, or the control of the consequential events (reinforcenents) occuxring with operant behavior. In this context, environmental control is synonomous with operant techniques. For the purpose of clarification, environmental control in this paper w1Il refer to control of the setting in which operant techniques are employed and not to the nanipulation of reinforcement contingenc1es.

\section{Theoretical Considerations}

There have been objections to Behavior Therapy employing Skinner's operant techniques in which the symptosi rerioval alone is criticjzed as being a "band-aia" approach. For example, when used in dealins with neurosis, it leaves the "basic causes" for neurosis uncured. Breser and hogeugi (1965) state that the cucrent arguents for a learning 
theory approach to psychotherapy are deficient on a number of grounds, one of which is the conceptualization of neuroses. In its essence, the conception of neuroses put forth by behavior therapists, is that neuroses are conditioned responses or habits (including conditioned anxlety) and nothing else. Breger and McGaugh state as background for their argument that behavior therapists stress the point that inferences about underlying factors such as unconsclous conflicts, impulses, defenses, etc., made by psychodynamic1sts are unnecessary and misleading, and that equating neurosis with symptoms, and symptoms in turn with habits (cónditioned responses), they are able to bring modern learning theory, with its "well established laws", to bear on the treatment of neurosis. The co-authors say that this view of neurosis has led behavior therapists into the precarious position where they must posit a learning experience for each symptom. This issue they have conveniently avolded by focusing on those neuroses which can be described in terms of specific symptoms (bed wetting, tics, phobias, etc.) and have ignored conditions such as neurotic depressions, interpersonal entanilements, etc.

On the other side of the controversy, Bandura (1961) says that psychotherapy rests on a very simple but fundamertal assumption that human behaviox is changeable through psychologicsl procedure. Fuxther he states that in the case of nost behavior disoriers, it is not the underlying motiva- 
tions that need to be altered, but rather the ways in which the person has learned to gratify his needs. For example, for a person displaying deviant sexual behavior, the goal is not removal of the underlying causes, 1.e., sexual motivation but the substitution of more socially approved, instrumental, and goal responses. Nowrer (1965) states that there is rothing diseased or abnormal about the emotional reactions of so called neurotic or psychotic individuals. On the contrary, in relation to the conduct and character (Iife style) of such individuals, their emotional reactions are quite appropriate. Thus there is a growing interest in psychotherapy as "behavior modification" in which it is held that the behavior of the individual, causes emotional reactions, not vice versa. Mowrer takes issue with the Freudian assumption that the way to change abnormal behavior is for another person (therapist) through treatment to chanze the "underlying emotions". He says that "exactly the opposite assumption now appears to be more valid; namely, the way to change disturbed (and disturbing) emotions is for the person himself to change his behavior."

Despite this controversy of theoretical positions, the plethora of reports on the successful modification of human behavior involvins a variety of contexts indicates that dehavior modification techniques are presently enjoying an era of popularity and pronise. One cen observe the bezinings of a science, the main corcern of which focuses upon socts? 
and complex behaviors; and it is besinniag to establish law ful relations between behavior and the variables that control 1t. The evolution of this science has forced it to move into such diverse areas as education, counseling, rehabijitation, and psychotherapy.

\section{General Applications}

In education, programed instruction plays an integral role in the modification of academic and social behaviors. Holland and Skinner (1961) and Gelss and Stebbins (1965) have published prosrams for learning introductory psychology. Fetarded chilaren at the Ranier school in Washington learn such skills as reading, writing, and arithmetic in a Programmed Leaming Glassroom (Pirnbrauer et.al., 1965). Cohen et.al., (1966) combined programmed instruction with a point system in a group situation designed to develop and maintain educational behavior in juvenile delinquents. Upon completing a unit of a program wj.th a score of at least 90 per cent, the student was eligible for taking an examination which earned him a generalized retnforces in the form of points. The points were worth one cent each and could be used to buy snacks, materials from a Sears ana Roebuck catalogue, or access to a lounge where his friends were. The points could also be usad to register for another prozrem, or to rent books, Ilbrary time, or an office with $a$ telephone. The results show a marited increese in educational behaviors over relacation be- 
havicus. Although the prosran was desiphed to focus on educational behavior, the authors report that in four and one half months the socinl behaviors of these delinquents seemed to match the standards set up by society.

Krasnor (1964) coments that he is struck by the behaviorist's uillingness to tackle the "way out" groups, such as psychotjos, retariates, anc delinquents whose behavior is often considered unmodifiable. Probebly the flrst report on the deliberate use of operant conditioning procedures in 8 . clinical stuation was that of Fuller (194\%). His subject wes a "vegetative fliot", an innate or areebleninded institution, whose behavior repertoixe consisted of opening his mouth, blinking hie ejes, and slight movements of his arms, head, and shoulders. Fullex shaped raising of the right arra to a vertical position by using a sugar milk solution roinforcer injectea into the suoject's mouth. The rate of the ari raising increased to three times a minute which allowed juet enough time for the injection and swallowing to occur. Becently, Fairwesther, Sanoiers, Kaynard, and Cressler (1969) have shown that chronic sohizophrenios can sucoessuliy participate la the sejection of personal goals provided that alternatives are jeilne? In comprehensible tems of performance and the clients are given responsibility for decision-maxins thet afeots their dally lives.

Counseling or interview approaches generally consider the structuring of a non-threetening or permissive situntion 
to be an important condition for behavioral change. It is expected that when a cllent repeatedly relates thoughts and feelings about events which, as a result of a previous history of associated aversive stimulation, elicit anxiety and guilt, but which the counselor does not disapprove or criticize, the client's maladaptive emotional responses will be extinguished throuth nor-reinforcement. It is also assumed that extinguished emotional responses will generalize to thoughts and feelings concerning related topics. In one investigation involving analyses of specific client-therapist interaction, Dittes (1957) found that permissive responses on the part of the therapist toward sexual statements, which were initially accompanied by strong enotional alousal, were followed by decreases in the client's autonomic (GSR) responses, resistive or avoidant remarks, and interruptions in speech. Abreactive procedures in which the clients are induced by hypnosis, drugs, and various other forms of anesthetics to relieve traumatic experiences, may also be explained in terms of soclal learning and the extinction process. Success with this program is reported by Lfttle anò James (1964) in recucing chronic anxiety, guilt, and avoldance responses in a client suffering traunatic war experiences. From a learning point of view, the critical factor in interviev approaches is the repeated elsciting of emotional responses which do not obtain reinforoenent.

In rehabiltation prosrams, the procedure of systematic 
desensitization or counterconditioning has been applied to a wide range of maladaptive behaviors. In this method, the therapist analyzes the stimulus determinants of emotional responsiveness and rank orders a list of situations to which the client reacts with increasing degrees of anxiety or avoidance. Then the therapist selects an anxiety neutralizing stimulus capable of inducing a competing condition of sufficlent strength to overcome the emotional reactions conditioned by the stimulus determinants. The arousal stimuli are presented in increasing order so that emotional responses are relatively weak and can be readily extingtilshed. The arousal potential of stronger stimulation is supposedly reduced by generalization of anxiety extinction from previous weaker stimulation. (Wolpe 1958) Recently, success with this metrodology in combination with vicarlous reinforcement, symbolic transfer, self direction, and group programs is reported in such diverse disorders as: academic anxieties, alcoholisth, chronic frigidity, exhibitionism, hyperesthesia, impotence, phobic disorders, psychosomatic disorders, and psychoses. (Bandura 1969)

What the future demands of Behavior Modiflcation techniques in clinical settings is the provision of unconfounced anc reproducible data regarains cxiterla measures of success, senerellty, ari durability of behavior changes effected by various treetreni procecures. Since 1938 operant technigues have noved from the arimal laboratory (E. F. Sxinner 1938) 
Into the schools, psychotherapeutic settings w1th individuals and hospltal wards with groups. The methodology has been flexible enough to move from stimulus-response to cognitive psychology. (Bandura 1969) The next frontier appears to be social psychology. The following research is almed at that frontier, bezinning with the deceptively simplest social structure, the mother-child cyad. Spplications to Chila Behavior

In a cogently written review, Brown (1969) relates that of the approximately 70 million children and youth urder 18 years of age in this country, some $?$ to 15 injlilion, depending on the criteria of psychological-psychiatric clessifications, heve enotional or behavioral problems that require assistance. Amoris children and adolescents, application of behavior modificatior techniques have been made in the following problem areas: 1) autistic, psychotic, schizophrenic behavior; 2) tantrums, destructive, ant1-social, predelinquent behaviors; 3) school problems, learning deficlts, fallures, disruptive and maladjustive behaviors in the classroom setting; 4) phoblas, anxieties, anri fears; 5) psjchosonatio disturcances; 6) speech developient and disturbences; 7) hyperactivity, and 8) development of social skills, cooperative play, and other soc1ally adaptive behaviors. Gelfand and Hartwann (1968) state thet behevion modification studies with children can convententy be classified in terms of: 1) deceleration of 
maladaptive behaviors, 2) the acceleration of prosucial beham viors, and 3) multiple treatment techniques. This system serves the purpose of establishing an outline with which one can review the literature. The focus of the following research will be to cover the range of techniques presently reported as opposed to the range of problem behaviors treated.

From the Central Midtestern Resional Educational Laboratories there is a report of striking results in the behavior and learning prozress of hyperaggressive pre-school chiidren. (Kamblin et.al., 1969) Enploying a token exchange systen in which desirable behavior of the subject Earns a token "pay off" with which "good" things can be bought, and undesirable behavior earns inattention, isolation or the removal of tokens already earned. The authors report: 1) ExtraordinarIly azgressive boys who had not previously responded to therapy have been tamed; 2) Two year olds have learred to read about as fast and as well as their five year old classmates; 3) Chilaren, too withdrawn to talk, have become better than average talkers; 4) Autistic children have developed func-tional speech, lost their bizarre and disruptive behavior patterns, and improved their relationships with parents and other children. More speciflcally, the token exchange system with hyperagresslve four year old boys increased attention during iesson time in a classroom to 95 per cent from the bascine rate of 8 per cent is thout the token exchange systen - over a 48 dey per1od. Asgression sequences decreased from a 
baseline average of 150 to an average? sequences on the last day. Cooperative sequences increased from a baseline average of 56 to an average of about 181 sequences. The authors explain that to make tokens meaningful, they were paired with a verbal "thank you", and an $M$ \& $M$ candy. Increasingly, the E "forgets" the $M$ \& $M^{\prime} s$ and after a few days, the children get no $M$ \& M's, just the approval. The authors explain the logistics in maintaining an effective token exchange system by varying the "goods" that can be purchased and maintaining the reinforcing potentlals of these goods.

A number of stuales have reported the use of extinction principles aimed at maladaptive behaviors in childrer. In general, the principle of extinction states that removal of positive reinforcemert, previously made contingent on a particular behavior, will decrease the strength or frequency of that behavior. One extinction technique that has been effectively applied to a wide range of behavior problems in a number of settings is the Time-Out procedure. This procedure refers to an arrangement in which the occurrence of a particular behavior is followed by a period of time in which a variety of potential reinforcers are no longer avallable. This procedure is also referred to as isolation because the subject is usually removed froil the enviromint where the particular behavior occurred and placer in a basically nonstimuating (non-reinforoins) situation for a periol of time. One of the first systematic epplications of this technique 
to the control of maladaptive behaviors in children was made by Wolf, Risley, and Mees (1964). The authors extinguished temper tantrums in a pre-school child who had serious behavioral and physical handicaps by placing him in his room contingent upon each tantrum. The door remained closed until the tantrum ceased. This procedure eliminated the possibility of continuous social reinforcement during tantrum episodes, and also provided for the reinforcement of non-tantruin behavlors by the door being opened to social contacts and play, contingent upon such behavior. Byrd (1969) points out the importance of clear communication by parents to children exhibiting undesirable behavior regarding the reasoning for using time-outs; namely, that the child knows his bad behavior causes cime-out. The author also emphasizes that parents should astutely observe, comment on, and reinforce good behavior that is incompatibie with the undesired behavior. Patterson and White (1969) have reviewed the literature concerned with time-out techniques and concluded that:

1) In a variety of situations, especially the classroom, To has been more efficient and effective than what right be termed "passive ignoring." 2) Although To of long duration has been used, short periods have the added advantage of allowing for an increase in the time avallable for positive relnforcement of acts representative of social skills. 3) size of To roons needn't be restricted to cramped quarters. Studias reporting effective use of To have used rooms about the size of a small bedroom. 4) Haintaining supervision of to while in use is desirable. It is necessary in studies where the chlid $1 \mathrm{~s}$ to be retumec to class immedately followins cessation of tantrun cenavior.

There is considerabie evidence thet the onset of ex- 
tinction procedures coincides with a temporary increase in frequency of the target behavior. (Bandura 1969) In some behavior disorders (self-destructiveness) even a slight increase becomes potentlally dangerous. In these cases, certain punishment or aversive techniques have been effectively applied. Bucher and Lovaas (1968) treated a seven year ola schizophrenic boy who delivered approximately 3,000 self-destructive blows during a 90 minute period when his restraints were removed. This behavior was almost totally eliminated in four sessions employing a total of twelve shocks made contingent on self injurious behavior. Tate and Baroff (1966), using a similar electric shock contingency in combination with a timeout procedure, effectively controlled a variety of selfdestructive responses in a nine year old psychotic boy who had. exhiblted the behaviors for flve years. The major criticisms directed at punishment techniques consider the duration of effects, possibie production of less desirable side effects, and actually increasing the target behavior. These criticisms generally view punishment in isolation from other variables, and in as much as they do so, they are correct. However, the reports cited above make special emphasis on providing consistent administration of punishment and powerful rewards for inconpatible elternative responses. Risley (1968) reports that brief prograus of electric shock and reinforcerent withdrewal are not only effective in removing seif injurious behavior of long standing, but they generaliy iriprove prosocial behaviors 
as well. It appears that once having focused a child's attention on relevant social stimuli, then appropriate behaviors can be more effectively positively relnforced. Recently, some pioneers in the behavior modification movement have developed a prograrn for the child with multiple problem behaviors. (Patterson and Brodsky 1966)

The procedure generally applied for accelerating prosoclal behaviors is shaping closer and closer behavioral approxImations to the desired goal. This procedure involves: 1) selecting reinforcers that are sufficiently powerful and durable to increase and maintain the desired behavior; 2) making these reinforcements consistertiy contingent on the desired behavior, and 3) providing a situation for inducing the desired behavior. This procedure has been employed by staats and his colleagues (Staats, Staats, Schutz, and Wolf 1.962) using canojy treats, trinkets, and tokens for buying toys as reinforcers to increase attention span on reading tasks with preschool children. The supposedly short attention span of brain-damaged and retarded children has also been markedly increasea by developing proper continsencies of positive reinforcement. (Naxtin and Powers 1967) The use of positive techniques often eliminates undestrable behavior by focusing positive reinforcement un competing desirable behavior. For example, Samris Johnstor, K̈elley, and Wolf (i.964) eliminated regressea craining in a three year old giri through aifferential relnforcenent of her walking instead of crawling. Allen, 
Hart, Buell, Harris, and wolf (1964) increased the frequency of peer as opposed to teacher interaction in a socially isolated nursery school girl by making the teacher's interests and attention contingent upon interaction with her peers.

An important objective of behavior modification programs applied to children is to endow social and symbolic stimuli with reinforcing properties. The development of these reinforcers is critical to the maintainance and generalization of behavioral changes affected in more restricted settings to natural environments. One methodology which shows considerable promise is that of vicarious reinforcement through model.Ing techniques. Bandura (1969) states that "virtually all learning phenomena resulting from direct experiences can occur on a vicarious vasis through observation of other person's behavior and its consequences for them." Jones (1924) successfully used the "method of social imitation" to eliminate children's fears. Chilaren lost their fear of a thite rebst. while watching other chilaren play with 15. Eandura (1965) describes a series of experiments in which children were shown films wherein adults, serving as models, displayed verbal and physical aggression. In onefizm, the model's astressive behavior was punished, in another it vas reinforced, and in a third, there vere no particular consequences. After the film, children veve tested for initictor, and those who observed the

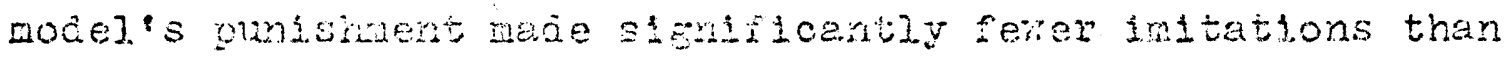
those who observed the rodal zenayded and those who observed 
no consequences. When offered an incentive to imitate the modeled aggression, however, all children perforned the sane. Bijou and Baer (1961) point out that the ch1ld is con tinuously reacting to and continuously being changed by environmental stimul1, and furthermore, the stimal are always belng changed by the reaction of the child. ore basic assump tion that has recelved considerable support from the behavior modification approach is that behavior, edaptive or maladaptive, is learned. In the case of parent-chlld interaction, there is strong evidence that much of the child's behaviox or misbehavior is maintained by the reinforcing properties of the parent. (B1 jou 1965; Patterson and Gullion 1968) Consequently, a number of programs and modiflers have focused on training mothers to deal with their children more effectively. The following research will concentrate on the varlous training programs for parents with child management difficulties.

\section{Training Parents In A Therapist Role}

Fortunately, in the light of the low ratio of child psychologists and psychlatrists to the increasing nuvber of children with cehavioral and emotional problems, parents and teechers with proper training can learn and efflciently apply behavior moditication techniques. The movement of behavior modifiers, workins wh chliaren, to trajn parents in a therapist's role is in contrast to the tractioma vien fin psychotherapy lin whoh it was thought thet only profeselone people

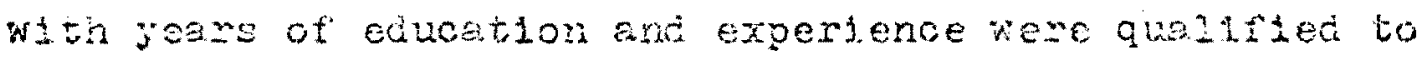


assume the role of change agents for children with behavioral problems. Recently, a number of professionals have developed and applicd training programs for parents to assume a therapist role in laboratories and in private homes.

In The Home. It is assumed by those professicnals working in the home that the most effective way to reduce the rate of maladaptive and/or deviant behavior and accelerate the rate of adaptive or prosocial behavior is to change the relnforcing contingencles of the "socially significant" people living with the child. The presumptions for focusing on the home environment include: 1) accelerating the changes in deviant behavior, 2) maximizing the generalization of behaviora? change across settings, and 3) increasing the durability of the behavior changes. (Patterson, Ray, and Shaw 1969)

Patterson, Ray, and Shaw (1969) began a training program for parents who were referred on the basis of having children with deviant behavior patterns. Following an initlal. Interview in the laboratory and the collection of baseIne data during ten sessions in the home, parents vere tralned to: 1) use the language and corcepts of soclas. learnIng by reading a programed textbook designed for th1s purpose (Eatterson and Gullion 1968), 2) observe and count child behaviors, 3) imitate intervention prograns with the child modeled by the experimenter, and 4) practice these specific programs with the experimenter absert. During the intervention programs, the experimenters use varlous reinforcing 
techniques for desirable behavior and various extinguishing techniques for undesirable behavior. The authors report that the results of this pilot study seem very promising. However, they aiscuss that economically it might be more beneficiel to work with groups of parents in the laboratory and intervene in the home only when group training proves inadequate.

Hirsch and Walden (1969) employed a group techrique with training 30 mothers with the principles and practices of behavior modification procedures. The training essentialiy involved: 1) group meetings consisting of highly organized lectures on reinforcement theory and infomal discussions, 2) individual discussion and management advice for specific behavior problems, 3) Individual application of learned prin-ciples to interaction in the horie, and 4) keeping da1ly records of child behaviors. The authors report that the frequency of the child's deviant behavior, as scored by daily record keeping and self reports, improved in the direction specified before treatment in $96 \%$ of the subjects. There was no objective observation of the child, however, to verify the subjective reports. Shah (1967) instructed a mother whose child demonstrated severe tantrum behavior to reep daily records. Upon one weeks completion, the mother's notes were used in defining the problematic contingencies that were maintaining the maladaptive behavior. These contingencies and besic operant principles were explained to the mother. Then a step-by-step outline vas formulated in which the moth- 
er was instructed to use a combination of time-out for tantrums and reinforcement for alnost any acceptable behavior. The mother was seen twice a week for two months until a "warm and positive relationship between mother and child was stabil1zed." Lindsley (1966) used a similar technique with fathers in a group and discusses the utilization of procedures including the "Suncay Box" and the "Point store". In supporting the contention that parents can be trained, the complete experimental procedure of behavior modification with specific behaviors in the experimental office, Johnson (1969) developed a set of parental instructions for the recording and managing of disturbing behaviors in two children. The instructions including applied extinction avolaance and faing techniques, were successfully carried out by the parents in 20 sessions. There have been a few manuals published which include the application of behavioral techniques in the home. (Patterson and Gulion 1968; Valett 1969; Wagner 1968)

In contrast to leaving the mother on her own in the home, relying on self reports and remote instructions, Peine (1969) makes a case for having a skilled therapist work vith the parents in their hone to train them in defining behaviors, recording and graphing behaviors, and building in reinforcers for the entire family. Zeilberber, Sampen, and Sloane (1968) aeveloped a list of instructions for a mother to follow which incluied systematic refnforcerdent and time-out procedures for hen hyperabressive four year oli son. In this progran, ez- 
perimenters went into the home and recorded the occurrence of target behaviors and reinforced the mother for following the instructions correctly (via social approval) and corrected the mother for not following the instructions correctly. The aggressive and disobedient behaviors of the child were clearly decreased by manipulating the parent consequences. Hawkins, Peterson, Schweid, and Bijou (1966) incorporated three observers for some 16 sessions of baseline data collection in the home. Following this baseline period, when an adequate rate of objectionable behaviors could be estimated, the mother was informed of nine objectionable behaviors that would be treated. She was shown three gestural signals that indicated how she was to behave toward her hyperagaressive, non-compliant four year old son, Peter: 1) Signal A meant that she was to command Peter to stop whatever objectionable behavior he was emitting, 2) Signal B meant thet she was to give him attention, praise, and/or affectionate physical contact, 3) signal C meant that she was to place Peter in his room and lock the door. A total of six experimental sessions were employed. Following the experimental sessions and a 24 day interval. three recheck sessions revealed that the nine objectionable behaviors were effectively modified. The authors note that Peter obtained much nore affection from his mother by an increased race of cesirable behaviors.

Peterson (1967) discusses the advantases and problems of carrying out behavior bodificatton programs with the therapist 
in the home. (Among the advantages he discusses are: 1) behaviors of concern to therapist and parent alike are more likely to occur in the home; in some cases, this is the only setting where the problem behavior occurs; 2) the therapist can accurately assess the contingencies of reinforcement between parent and child only with first hand observation; 3) generalization of treatment effects across setting and across pexsons; 4) the therapist can be sure that the mother emits the correct response at the correct time for the correct behavior, and 5) relevant uncontrolled variables may be observed in the home. Among some of the problems reviewed were: 1) the presence of an observer changes the home environment; 2) relevant signaling devices force the parent to be at a certain vantage point, and 3) recording techniques do not allow observation usually of serlous behaviors that occur seldomly. The point this author makes is well taken but on the other side of the coin, many therapists have been very successful. in employing behavior modification techniques with parents in the laboratory.

In the Iaboratory. Bell (1964) noted that by controlling the environment in which children's problem behaviors occur, reliable observation can determine the relevant parent behaviors that maintain them. Findley (1966) has pointed out that there is very limited experimental analysis of human behaviox. He cites as reason for this state of affalrs the constraint of using standardized environments in which 
reliable observations can be made, contaminating variables controlled and relevant variables discovered.

A few investigators report the use of laboratory environments in modifying mother-child interaction difficulties. Russo (1964) reports using a treatment which involved simple reinforcement of desired behavior (cooperailon, sociability, and friendly conduct) and extinction of undesired behavior (outbursts, rudeness, loudness, etc.) by withdrawal of reinforcement. Although he reports success in the sense that undesirable behavior decreased in frequency, it is impossible to analyze the relevant variables maintaining the deviant behavior and those responsible for changing 1t. Stralighen (1963) reports success with a method of desensitization combired with encouragement of appropxiate behavior in a case where the mother had become an anxlety arousing stimulus to her child. By her regimental and domineering influence, the mother had come to elicit anxiety in the child by her simple presence. Using a desensitizing technique as described by Wolpe (1958), Straughan induced relaxation in the child playing independently in a playroom and then slowly introduced the mother with closer and closer physical approximations. The mother was instructed to encourage the child's appropriate behavior. Again the report does not permit analysis of the relevant varlables leading to the mother's anxiety arousing potential or those variables related to desensitizing this potential.

B1jou (1965) used a playrooil connected to an observation 
room by a one-way glass mirror and a microphone. Two observers recorded all of the child's verbal and non-verbel behavior and all of the mother's verbal and non-verbal behavior immediately following the child's behavior. Behaviors related to the mother's complaint (he is always commanding me to do things) were considered deviant. Cooperative behaviors, verbal and non-verbal, were considered incompatible with the deviant behaviors and very desirable. Two sessions provided enough information for the identification of the problem behaviors. Two further sessions provided baseline measures on the frequency of occurrence of the chlld's cormanding and cooperative behaviors and the mother"s responses to them. In the next two sessions, the mother was instructed by nay of a lient signal to ignore commanding behavior and attend in any way she thought natural to cooperative behavior. Commanding behavior decreased over baseline sessions while cooperative behavior increased. In order to further establish the maintaining effects of the mother's consequential behavior, the next two sessions contained the instructions to behave as she did in the baseline sessions and no instructions via the signal. vere given. Azain the child's commanding behavior increased and cooperative behavior decreased over the rates obtained in the instructional session. The next sessions which were still in progress at the time of the writing would revert to having the mother isnore comanding and reinforce cooperation. In this stage, they help the mother form accurate discriminations of commanding anci cooperating by flashing a light when she makes 
the correct decisions. The 11ght is assumed to have a reinforcing function in shaping up discrinination. One question raised by this study concerns the extent to which laboratory acquired behavior generalizes into the home.

Bernal, Duryee, Pruett, and Burns (1967) report the use of a clinic situation similar to that employed by Bijou in shaping a mother to 1 gnore, express arger, order to stop, and punish abusive behavior of her $81 / 2$ year old "brat". These conditioned aversive stimuli assumed a control function in reducing undesirable behavior. It is interesting to note that these aversive stimuli assumed the function of negative reinforcers when their withdrawal was made contingent on "good" behavior. Along with teaching the mother to follow through with these control neasures, the authors shaped up mateine? reinforcements made contingent on only good behavior. The results show an increase in the "brat's" complying behavior w1th a decrease in self abuse, mother abuse, and a host of undesirabie behaviors. Video taping of the sessions provided observer reliability ratings, observational learning sessions in wich the mother was reinforced while observing her aporopriate behaviox and not reinforced while observing her inappropriate behavior.

Whiler, Hinkel, Peterson, and Morrison (1965) used a similar procalure to that of Berral et.al., (1967) in changIns the nothex's refriforcenent contingencies that maintained problem behaviors in their children. The techrique involves five stages: 1) Escabijehlng baselines on child and mother 
behavior; 2) Helping the mothers to discriminate deviant behaviors from their incompatible counterparts in their children; 3) Shaping mothers to make social reinforcement contingent on the compatible behavior while lgnoring the deviant behavior; 4) Changing these contingencies to establish their maintaining function, and 5) Returning them to their desirable properties. The authors report success in three cases.

The above studies concentrate on the methodology of shaping mothers to shape their children's behavior. However, the question arises concerning how "functionally equivalent the laboratory exemplars are to the natural environment." (Uilman and Krasner 1965) Instructions to the mother before entering the playroom generally consisted of, "Just play with as you might at hone." The laboratory restrictions imposed are not reported as contributing variables to treatment effects. Because the natural environments of children are far less complex than those of adolescents and adults, they should produce fewer difficulties for systematic laboratory control and reproduction. Hanf (1968), at the Crippled Children's Division of the University of Oregon Medical School, has developed a two stage program to control mother-child interactions in a variety of standard laboratory environnents. 


\section{HANE'S PROCEDURE}

Initially, Hanf (1968) conducted detailed interviews, behavior oriented in focus, with a pilot group of eight mother-child $(M-C)$ pairs who were referred to the behavior modification program for severe management difficulties. During tris interview, mothers reported those situations in which management difficulties occurred most regularly, the child's behavior on those occastons, and their own behavior on those occasions. From these reports a set of laboratory standard envirorments were empirically derived which rexe considered to be malogs of those daily environments in which M-C interaction difficulties occurred. The set of standard laboratory environments included: mother occupied, child to play alone (A), child's game and rules (B), mother's game and rules $(C)$, visitor in the room $(F)$, mother leaves the room $(G)$, and clean-up (Z). A complete list of the construction of these and other standard laboratory environments based on Ms' description of their problems is reproduced in Apperidix B. No complaints of the pilot group were omitted from this list and Hanf (1968) reported that complaints of some 24 subsequent mothers fell neatly into these categories.

It was assumed that use of the standard laboratory environments would: 1) increase the rellability of observation, 2) provide the necessary conditions for valid within and be- 
tween dyad comparisons, 3) standardize conditions for reniication and study of behavioral sequences and their development over time, 4) expedite the behavior modification process by providing the environmental stimuli that produce the reported problem behaviors, and 5) increase the probability of generalization of acquired behaviors to natural environments.

Hanf's procedure involved collection of baseline data by a team of trained observers assigned to each $\underline{\mathrm{M}}-\mathrm{C}$ pair. Data were collected on operationally defined behaviors for the mothers and their childrer in the standard laboratory environments that matched their specific complaints, (disclosed in an inftial interview). Three to four baseline sessions were conducted until the data reached consistency and the specific problems could be defined. Only those laboratory environments in which the problem behaviors occurred provided the setting in which behavior modification was carried out. Following the baseline perlod, the team shared with the mothers their observations, hypotheses, tabulated data, and audio-video tapes in a treatment interview. The goal of this interview was to train mothers to observe, think, and speak about specific behaviors that occurred in the baseline sessions.

Following the treatment interview, the two-stage treatment profram commenced. The goals of the first stage were to increase mothers' attending and following behaviors contingent on their children's desirable behaviors, and to increase the mothers' repertoires of contingent verbal and physical rewar- 
ding behaviors. The goals of the second stage were: 1) shape mothers in giving simple, explicit, and direct commands, 2) get mothers to use rewarding behavior, leamed in stage 1 , contingently on their children's compliance with commands, and 3) increase the effective use of aversive consequences (1.e., warning, time-out, spanying sequence), contingent on children's non-compliance to commands. During the treatment sessions, a mother received instructions, rewards, and criticisms via a wireless communication system while interacting with her child in the standard laboratory environments. When it was deemed appropriate by the team, modeling techniques were employed to develop the mother's repertoire of particular behaviors.

Because of the procedure of this two-stage program, (1.e., teaching Ws to become dispensers of positive soclal reinforcement and then teaching them to use control techniques effectively) standard laboratory environments, child's gaine and rules (B) and mother's game and rules (C) were used primarily in the application of behavior nodification tech.. niques. It can be seen from the goals that broad response classes were the focal point of this program as opposed to single target behaviors. The duration of this program involved an average of 15 sessions. Sessions occurred twice weekIy and were extended over a 2 to 3 month period. The findings of this program concluded that the use of standardized laboratory environments facilitated the analysis 
and modification of relevant variables that function to maintain problem behaviors. In $\underline{M-C}$ interaction. The use of these environments has also provideọ the potential for more accurate observations of the acquisition and generalization of behaviors in one or more different but related environments. At the time of this writing, Hanf was conducting research in the computation of ratios of mother and child behaviors which, It was thought, would enhance definitions of problem behaviors in dyad interaction, facilitate the development of criteria across pairs for optimal contingencies, and provide for ready analysis of the data. One goal of this research was the provision of a prediction syster which would have the potential of identifying specific behaviors and behavioral deficits in mothers with management problems. (Henf 1970) 


\section{THE EFFECTIVENESS OF GNVIRONMENTAL CONTROL}

\section{Statament of The Problem}

One aspect of Hanf's procedure which recelved considerable attention in the following experiment was the effectiveness of using standard laboratory environments in a behavior modification setting. Throughout the preceding research, it was noted that for behavior to be modified it must first be observed. Howevex, behavior modiflers have not addressed themselves to the development of a rellable procedure designed to produce on the overt level, problem behavlors of focus for modification techniques. In the reported clinical settings, therapists dealing with parent-child interaction difficulties have provided for the parents vague instructions. These instructions were not specifically designed for the elic1tation of problem behaviors that became the target of modification techniques. Other therapists have intervened in the home environment where the necessary stimulating conditions for parent-child interaction difficulties are frequently present, but not controlled. When Hanf (1968) developed standard laboratory environments for the employment of behavior modification techniques, the assumption was that these environments would reliably increase the probability and frequency of occlarrence of a broad class of problem behaviors across I-C pairs. The presont reseeroh ras dosigned to test this 
assumption.

The purpose of this experiment wes to discovex whether or not standard laboratory environments constructed primarily by specific instructions to the parents were effective in increasing the probability and frequency of occurrence of a broad class of problem behaviors across M-E pairs. Utilizing the baseline procedure developed by Hanf (1969) the present experiment atterpted to design a control technique for examin1.ng the effects of standard laboratory environments on increasing the frequency of $\mathrm{M}-\mathrm{C}$ interaction difficulties. The development of a control technique involved the designing of a free-time environment $(X)$ which would include all constant variables present in the standard laboratory enviroments except for specific instructions which cued $y_{1}$ to behave in a particular way. In general, it was hypothesized thet those behaviors which constitute interaction afficulties would occur with less frequency in the free-time (no specific instructions) environment $(X)$ than in the standard laboratory environments which were constructed by specific instructions to $M$. Interaction difficulties vere defined as an increase or decrease in the frequency of specific behaviors that were to be the focus of extinction or sheping techniques respectively. For example, it was hypothesized that ferer commands, 3 ives up control, and complias would occur in free-time environment ( $X$ ) thar in standard laboratory anvironments, mother's game and mi]. as (C), and clean up $(Z)$. 
METHOD

\section{Subjects}

The Ss were $12 \underline{M}-\underline{C}$ pairs who were referred to the behavior modification program from various clinics in the Crippled Chilaren's Iivision of the University of Oregon Medical School for management problems so severe that parents in the home and staff specialists could not manage $\mathrm{C}$. In general, Cs were classified as "futile to manage on take care of, severely hyperact1ve, unrcachable, or retarded." All Cs had one or more of the following chronic, hand1capping, physical alsabilities: 1) hyperactivity, 2) deafness, 3) tbsence of useful speech, and 4) mental retardation. All Cs ranged between 2 and 6 years of age. All Ms in the study rere white and ranged in soc1o-economic and educational. categories from welfare to hish income levels, ghetto to surburban residents, and grade school to college graduates.

\section{Equipnent and Leboratori settins}

Volunteer assistants consisting of csyohologv interns, graduate and undergraduate psychology majors, and a volunseer mother with a college degree constituted the various four wan

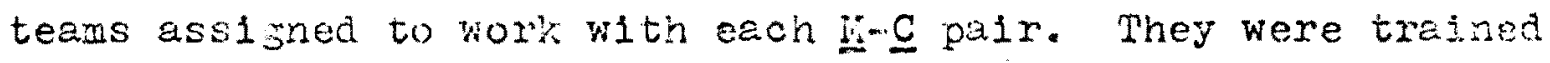
to carry out tasis involving the use of laboratory eculpment, and the transformation of data from machine output. Thejr 
participation in the program ranged from one month to four years.

An Esterline-Angus 20-channel event recorder (EsterlineAngus Instrument Compary, Indianapolis, Indiana), a Bus-1nthe-Far one-way wireless communication system (Farral Instrument Company, Grand Island, Nebraskal, and an Ampex V1deo Tape Recorder constituted the equipment necessary for reliable observation and recording.

Two roums connected by a one-way mirror provided the setting for observing and recording activities. A standard supply of toys provided the milieu for both active and quiet Individuals and were avallable for each session; however, each pasr received no more or less than flve different kinds of toys throughout their program.

\section{Specific Procedures}

In1tial Interview. All Ms appeared for inltiel interviews where information was obtained concerning specific behaviors, conditions, and occasions which led to $\mathbb{M}-\underline{C}$ interaction difficulties (Fanf 1969). Following this interview, sil MS were: 1) acquainted with the program procedures - this included telling Ms that reproduction of those dally situations In which their problens occurred would be attempted in the labcratory via a set of instructions, (standard laboratory environnents), 2) show the observation room and equioment, and 3) Introduced to the nembers of the team who would be woxins with then. 
Baseline Data Collection. After introduction to the program, all $\mathbb{M}-\mathbb{C}$ palrs appeared in three sessions on three separate days for baseline data collection. Upon entering the clinic, a secretary presented $\mathbb{M}$ a list of instructions which described the sequence of, and standard laboratory environments planned for the particular $\mathbb{-}-\underline{C}$ pair on the particular day. The standard laboratory environments were constructed by specific instructions to Ms via this Iist, and later in the laboratory by a wireless communication system to avold any confusion. For example, a list of instructions might include the following: "Hello, Mrs. Doe. Today let us proceed as follows: When we talk with you (via the wireless conmunication system) get John to play in a game(s) you choose and keep him at this. You can change games but keep him at whatever you choose. Do not choose games that he likes especially, (standard laboratory environment, mother's game, c). When we talk with you again, you play whatever game or activity John chooses. It is his choice of games and his rules, (standard laboratory environment, Child's game, B). Then, when we talk with you again, clean up. Get John to put toys wherever you choose, we do not care. The liea is to get him to do things you ask him to do, (standard laboratory environment, clean-up, $z$ ). That is all for today. We will see you next Vednestay, April 8 th, at nine o'clcck in the mornir.3. Thank you."

A table of all laboratory environuents and their corresponding instiuctions is included in Apperilix $C$. Since the pre- 
vious worls by Hanf (1969) manifested thot almost without exception, standard laboratory environments, child's game and rules ( $B$ ), mother's game and rules (C), and clean-up ( $Z$ ), provided the najor occasions across pales during which problem behaviors occurred, these were incorporated in the present study

Prior to the baseline data collection in these standara laboratory environments, a free-time environnent $(x)$ was constructed in the following manner: After $M$ had a chance to read the list of instructions presented by the secretary, she was greeted by $E$ who introduced himself as a member of the team that would be working with her. Fe then sald, "If you will come with me to the playroom, we yill be abie to get startcd shorty...(on the way to the playroom)...We prefer to have you and your child stay cown here while we are getting set up with the equipnent... (at the playroom door)... It will take us a few minutes and when we are ready, we will let you know via the wireless communication system." E then gave her the Bus-in-the-Ear device and closed the docr. The construction of a free-tine environgent $(x)$ was designed to procuce a situation where no specific instructions were presented Which would cue a mother to behave in a partioular way. All otrer cxtrinsic vaxiables held constant in standard laboratory envionments, child's geme and rules (3), mother's geme and

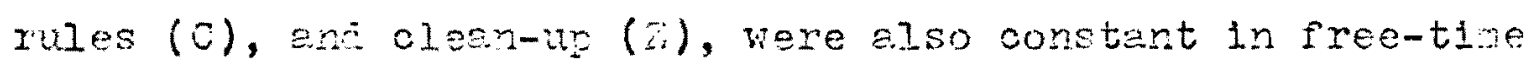
environment $(x)$. The purpose of free-tims environnent $(x)$ wes to procice a situation not subject to specific instrue- 
tions where $\mathbb{E}-\underline{C}$ behaviors could be rellably observed and recorded.

It vas considered by the team of observers that free-time environment $(X)$ should logically occur first in the sequence of standard laboratory environments. The rationale for this structuring was that a free-time environient could be established only by avoiding as much as possible any specific instructions which would clue the is to behave in a particular way. It was assuined that the free-time environment $(X)$ would produce as close as possible walting room behaviors not influenced by specific instructions and should therfore occur first in the sequence of presentation. Also team cursideration concluded that standard laboratory environment, clean-up ( $(2)$, should logically occur last in the sequence beceuse it would not make sense to the child to clean up the toys in the room and then begin playing with them again.

Following these considerations, it was the design of this experiment to hold all extrinsic variables constant in the standard laboratory environments and free-time environment $(x)$ and vary only those instructions which constituted each enviroment. The specific instructions which established standard laboratory environments, child's game and rules (B), mother's game and rules (C), clean-up ( 2 ), and no specific instructions wich established free-time environment $(X)$ were the incependent variables of this stury. Except for the logical orcer of free-time environment (x) occuring filst and cieen-up environment $(Z)$ occuring last 
In the sequence of presentation, the design attempted to counterbalance and randomize the sequence of child's game and rules (B) and mother's game and rules (C). This was done so that if order effects were present, they would be spread over all treatment effects and vould belance out. The counterbalancing involved a $B C, C B, B C$ order for four $M-C$ pairs and a

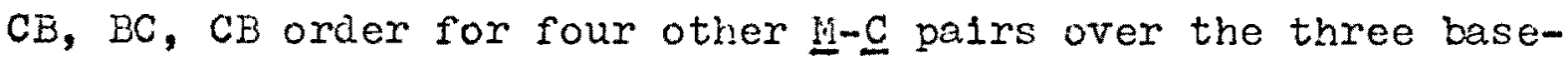
line sessions. The randomizing involved a flip of the coin where heads decided $B C$ order and tails decided $C B$ order for four $\underline{N}-\underline{C}$ pairs over three baseline sessions. Then a comparison of data was conducted to determine whether or not order effects were present in this experiment. (See Results)

Eight behaviors which had been operationeliy derined were selected from Hanf's previous work (1969) with 30 in-c pairs on the besis of their cormon occurrence across $y-C$ palrs and their ability to delineate interaction difficulties. These behaviors were observed and recorded for each $\underline{\underline{H}-\underline{C} \text { pair }}$ in each environment: free-time $(X)$, child's game and rules (B), mother's game and rules (C), and clean-up (Z). Appendix D contains a list of these behaviors and their operational definjtions. Each behavior was observed and recorted in rate-per-minute values in each of the environments. Each environment wes progranmed for a duration of five minutes since 1t was found in a pilot study by zanf (1969) that longer perlods of time, i.e., 15-20 alnutes per envirorment produced rate-yer-minute values sialier to those obtained in the 5 rinate perlok. 
Reliability. A reliability training session was conducted over a two week period involving some 18 hours of recording behaviors observed on audio-video tapes. The tapes were proviously recorded during baseline sessions with $\underline{\underline{H}}-\underline{C}$ pairs. The final reliability check on a four nember team of observers included data on eight behaviors in the four differ.ent laboratory environments, $X, B, C$, and $Z$. All behaviors were observec and recorded by two observers. Data was compiled and transformed from the 20-channel event recordex tapes by two independent observers who later collaborated on differences. Inter-observer reliability coefficients were computed and yielded the following results for the elght behavioxs: 1) Commands, $.90,2)$ Follows in C's play, .88, 3) Gives up control, .946, 4) Asks Questions, .914, 5) Rewards, .975, 6) Indepencient Play, .76, 7) Interaction, .941, and 8) Complies, .89. It was concluded that inter-observer reliability was obtained. None of the observers were informed about the hypotheses of this study.

\section{Hyootheses}

The purpose of this experiment was to deteinine whether or not standard laboratory environaents constructed by specific instructions to functioned to increase the probability and frequency of occurrence of a broad class of problen behavione acroso i-C pairs. Problem behaviors were consicered to be those behaviors of focus in the analysis of interaction dificultes. The eight behaviors derlned in Apperdix b vere 
used as the criteria in this experiment. Hypotheses concerning the effects of standard laboratory environments, child's game (B), mother's game and rules (C), clean-up (Z), and freetime environment $(x)$ on the elght criteria behaviors were formulated and tested. Specifically, the major hypotheses included:

1) There would be a decrease in the frequency of Gives Up Control as a function or environment $(X)$ and an increase in this frequency as a function of environments $(C)$ and $(Z)$.

2) There would be an increase in the frequency of Independent Play as a function of environment $(X)$ and a decrease in this frequency as a function of environments (B), (C), and (Z).

3) There would be an increase in the frequency of Interaction as a function of environnent (B) and a decrease in this frequency as a function of environment $(X),(C)$, and (Z).

4) There would be an increase in the frequency of Follows in C's Play as a function of environment $(B)$ and a decrease in this frequency as a function of environment $\left(X_{n}\right)$.

5) There would be no difference in the frequency of Rewards as a function of the environments $(X),(B),(C)$, and $(Z)$.

In conjunction with these major hypotheses the following supplementary hypotheses were formulated and tested:

1) There would be an increase in the frequency of Commands as a function of environments (C) and (2) and a decrease in this frequency as a function of environments $(X)$ and $(B)$.

2) There would be an increase in the frequency of Complies as a function of environments (C) and (Z) and a decrease in this frequency as a funotion of environients $(X)$ and $(B)$.

3) There would be an increase in the frequency of Asks Questions as a function of environment (B) anc a decrease in this frequency as a function of environiments $(X),(C)$, and (Z). 
RESULTS

A two factor repeated measures design was employed for analysis of the data. (Winer 1962) There were four levels of the treatment factor and three levels of the day factor. All mothers and children were observed under the four treatment conditions on three separate days. The rationale underlying this design ves that free-time environment $(X)$ and standard laboratory environments (B), (C), and ( $Z$ ) were viewed as separate treatments given to all $\mathbb{M}-\underline{C}$ pairs, and all $\underline{M}-\underline{C}$ pairs were measured on the same criteria. The criteria measured in each of these environments included all. of the elght behaviors defined in Appendix I. An analysis of variance was conducted on each of these criterion measures. The day by environient interaction was considered important in order to determine whether the frequency of behaviors changed across environments as a function of the three different days on which they were observed and recorded. Post-hoc comparisons were conducted to determine the effects of each environment on the frequency of each behavior. All hypotheses were tested at the .01 level of significance andor the .05 level of significanca.

The fixst major hypothesis may be stated as follows:

Fo $_{0}$ There vould be no difference in the frequency of Gives Up Control as a function of the environients $(X),(B)$, (c), anc (z).

$H_{1}$ : There would be a cecrease in the frequency of Gives 
Up Control as a function of environment $(X)$ and an Increase in this frequency as a function of environments (C) and ( $z$ ).

Table I includes an AB Summary of Observed Data, Analysis of Varlance, and a Test on Heans Using Newman-Keuls Procedure on Gives Up Control.

\section{TABLE I}

AB SUMAPY OF OBSERVED DATA, ANALYSIS OF VARIANCE, AND TIEST ON MBANS USING NHMMAN-KEULS PROCEDURE ON GIVES UP CONTROL

\section{AB SUMMARY TABLE OF OBSERVED DATA:}

Environments

(i)

\begin{tabular}{l|l|l|l|l|l}
\hline & $b_{X}$ & $b_{B}$ & $b_{C}$ & $b_{Z}$ & Total \\
\hline$a_{1}$ & 9.6 & 37.8 & 196.9 & 261.6 & 505.9 \\
\hline$a_{2}$ & 5.2 & 0.0 & 186.8 & 178.8 & 370.8 \\
\hline$a_{3}$ & 13.3 & 5.6 & 212.2 & 155.5 & 386.6 \\
\hline
\end{tabular}

\section{ANALYSIS OF VARIANCE OF GIVES UP CONTROL:}

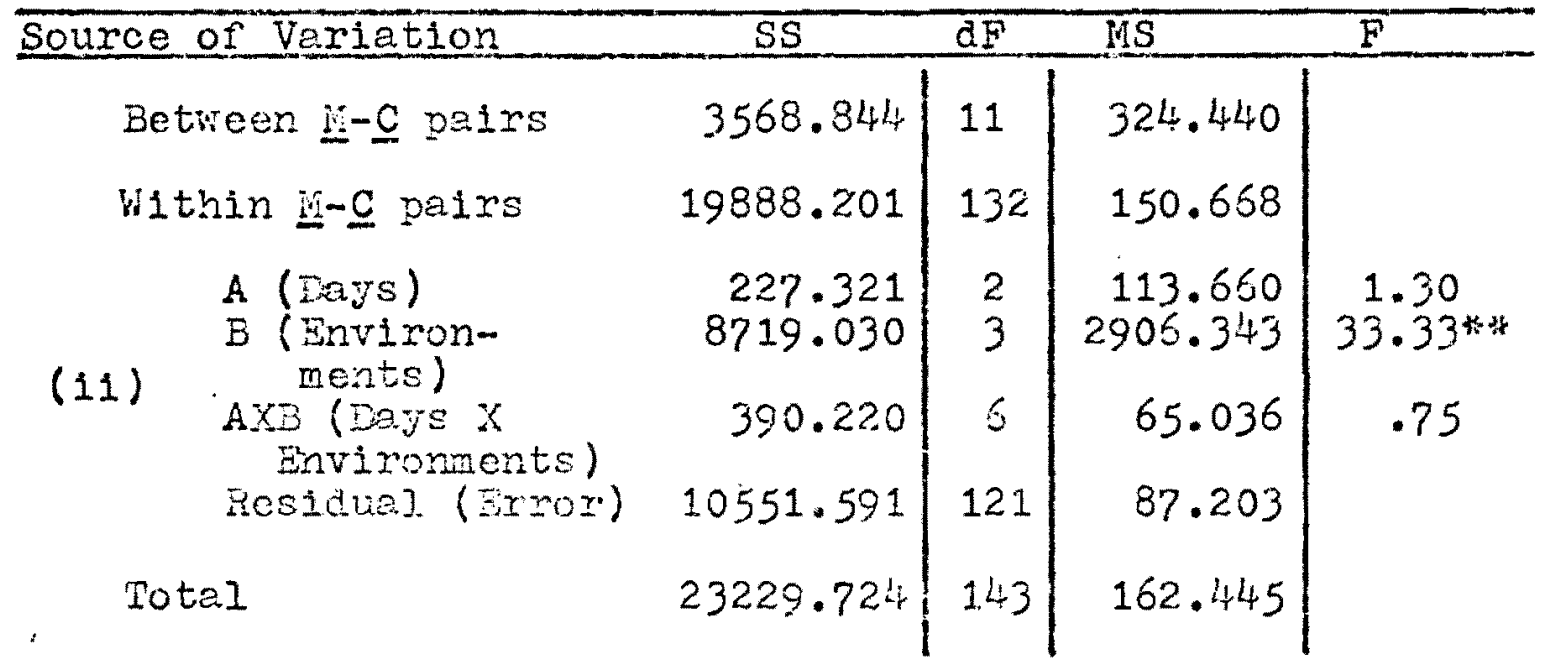


TAELE I-Continued

TEST ON HEANS USIHG NEWIAN-KEULS PROCEUURE:

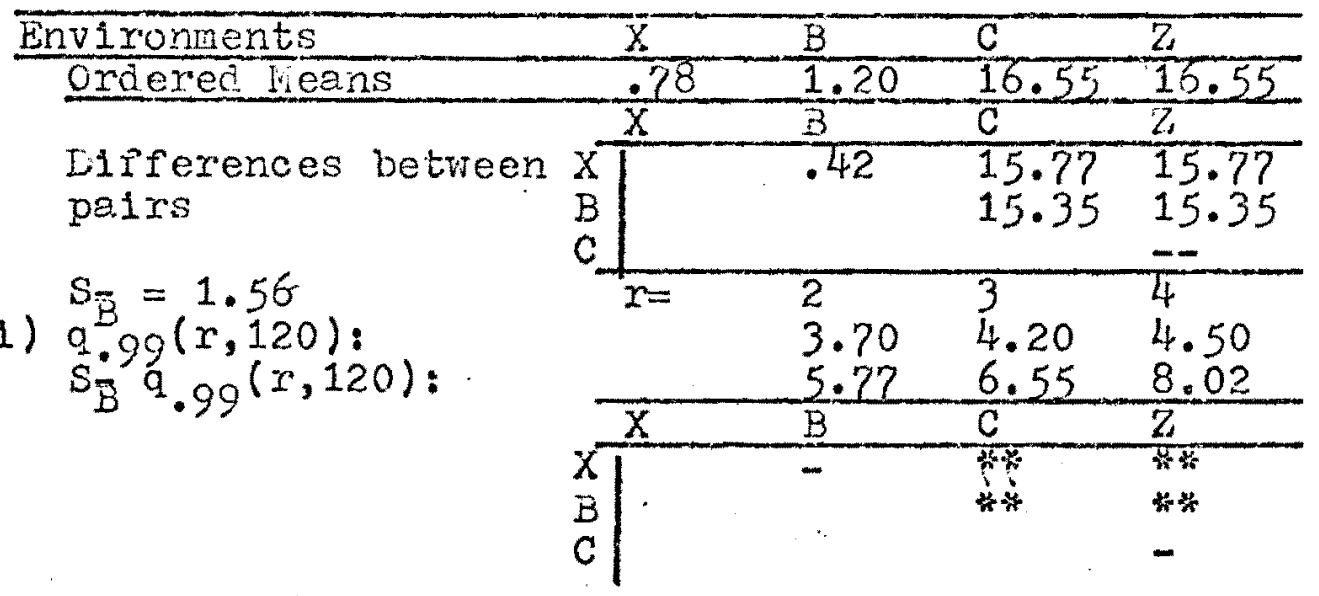

In view of the analysis of variance results in part 11 of Table I, the null hypothesis is rejected at the .01 level of significance since $F_{99}(3,120)=3.95$. There vere no significant interaction effects between days and environients on this criterion. The test on means in part ili of Table I shwos that the mean frequency of Gives Up Control in environment $(z)$ is statistically different from the mean frequency in environtients $(X)$ and $(B)$. The mean frequency of Gives Up Control in environment (C) is statistically different from the pean frequency in enviroments $(X)$ and $(B)$. No other differences between means were statistically significant at the .01 level for the Neman-Keuls test. The alternative hypothesis thet there would be a cecrease in the frequency of Gives Up Control as a function of enviromment $(X)$ and an increase in this frequency as a fuction of environments (C) and $(z)$, is accepted at the .01 level of sientificance since $5-9.99$ 
$(4,120)=8.02$ and $S_{\bar{E}^{q}} .99(3,120)=6.55$ respectively.

The second major hypothesis may be stated as follows:

$\mathrm{H}_{0}$ There would be no difference in the frequency of Independent Play as $\&$ function of environment $(X)$, $(B),(C)$, and $(Z)$.

$\mathrm{H}_{1}$ : There would be an increase in the frequency of Independent Play as a function of environment $(X)$ and $\varepsilon$ decrease in this frequency as a function of environments $(B),(C)$, and (Z).

Table II includes an $A B$ Summary of Observed Lata, Analysis of

-Variance, and a Test on Means Using Newman-Keuls Procedure on Independent Play.

TABLE II

AB SUMMARY OF OBSTEVED DATA, ANALYSIS OF VARIANCE, AND TEST ON WEANS USING NEWMAN-KEULS PROCEDURE ON INDEPENDENT PLAY

AB SUNAARY OF OBSBYVEY MATA:

Environments

(1)

\begin{tabular}{l|l|l|l|l|l}
\hline & $b_{x}$ & $b_{3}$ & $b_{C}$ & $b_{z}$ & Total \\
\hline$a_{1}$ & 186.9 & 154.2 & 75.4 & 72.7 & 489.20 \\
\hline$a_{2}$ & 184.9 & 131.8 & 129.8 & 91.7 & 538.20 \\
\hline$a_{3}$ & 249.0 & 103.0 & 52.3 & 37.3 & 441.60 \\
\hline
\end{tabular}


TABLE II--Continued

ANALYSIS OF VARIANCE OF INDEPENDENT PIAY:

\begin{tabular}{c|r|r|r|r}
\hline Source of Variation & \multicolumn{1}{c}{ SS } & \multicolumn{1}{c|}{ C. } & MS \\
\hline Between M-C pairs & 7486.116 & 11 & 580.556 & \\
W1thin M-C pairs & 17910.004 & 132 & 135.681 & \\
A (Days) & 97.21 & 2 & 48.605 & .38 \\
B (Environ- & 2894.792 & 3 & 964.930 & $7.45^{34 *}$ \\
ments) & 624.863 & 6 & 104.143 & .80 \\
AxB(Days X & Envirunments) \\
Residual (Error) & 692.701 & 121 & 129.558 & \\
Total & 25396.12 & 143 & 177.595 &
\end{tabular}

TEST ON MEANS USTNG NENHAN-TEULS PROCEDURE:

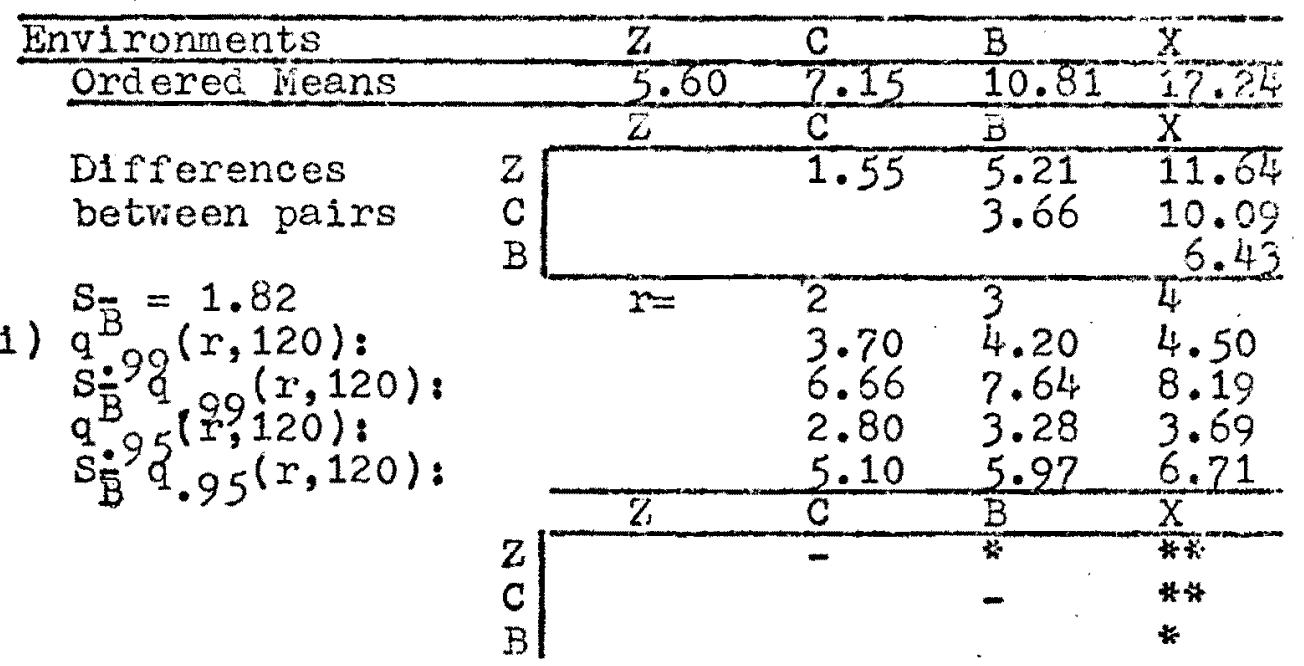

The results of the aralysis of varlance in part 11 of Peble II lead to the rejection of the nuli hypothesis at the .01 level of sisnificance since $F_{.99}(3,120)=3.95$. There vere no significat aay by environgent interacion effects since F.99 $(6,120)=2.96$. The test on means in part 1it of ilable II shots thet the aean frequenoy of Intependent play lin environ- ment $(x)$ is stetistically different from the dean frequency in 
envirunments $(B),(C)$, and $(Z)$ since $S_{\bar{B}} q .95(2,120)=5.10$, $s_{B} q_{.99}(3,120)=7.64$, and $s_{\vec{B}} q .99(4,120)=8.19$ respectively. It was noted that the difference in the mean frequency of Independent Play between environments $(X)$ and $(B)$ was statistically significant at the .05 level, and the difference in this frequency between environments $(X)$ and $(C)$, and $(X)$ and $(Z)$, was statistically signiricant at the .01 level. Thus, the alternative hypothesis that the frequency of Independent Play would increase as a function of environment $(X)$ and decrease as a function of environments $(3),(C)$, and $(Z)$, was accepted. The third major hypothesis was stated as follows:

$\mathrm{H}_{0}$ : There would be no difference in the frequency of Interaction as a function of environients $(X),(B)$, $(C)$, and (z).

$\mathrm{H}_{1}$ : There would be an increase in the frequency of Interaction as a function of environment (B) and a cecrease in this frequency as a function of environments $(X),(C)$, and $(Z)$.

Table III includes an AB Summary of the Observed Data, Anelysis of Variance, and a Test on Means Using Newman-Keuls Procedure on Interaction.

\section{TABLE III}

A.3 SUMHARY OF OESERVED DATA, ANAIYSIS OF VARIAICE, AND TEST ON WEANS USING WEMAN-KUULS PROCEDURE OA INISRACTION 
TABLE III--Continued

AB SUIMAPY OF ODSERVED DATA:

Environments

(1) $\frac{n}{8}$

\begin{tabular}{l|l|l|l|l|l}
\hline & $b_{X}$ & $b_{B}$ & $b_{C}$ & $b_{Z}$ & Total \\
\hline$a_{1}$ & 271.9 & 312.9 & 209.7 & 111.1 & 905.6 \\
\hline$a_{2}$ & 226.8 & 345.0 & 204.0 & 192.0 & 967.8 \\
\hline$a_{3}$ & 163.8 & 250.5 & 126.1 & 134.6 & 680.0 \\
\hline & 667.5 & 908.4 & 539.8 & 437.7 & 2553.4
\end{tabular}

ANAIYSIS OF VARIANCE OF INTEPACTION:

\begin{tabular}{|c|c|c|c|c|}
\hline Source of Variation & SS & $\mathrm{dF}$ & TS & $\mathrm{F}$ \\
\hline Between $M-C$ pairs & 6210.614 & 11 & 564.601 & \\
\hline Within M-C pains & 25570.950 & 132 & 193.719 & \\
\hline$A(\overline{\bar{L}} \overline{\mathrm{y} S})$ & 955.508 & 2 & 477.754 & 2.80 \\
\hline (ii) $\quad$ B (Environ- & 3508.035 & 3 & $169 \cdot 345$ & $6.85 \%$ \\
\hline AXB ( Days $X$ & 446.262 & 6 & 74.377 & .44 \\
\hline $\begin{array}{l}\text { Environments ) } \\
\text { Resiaual (Error) }\end{array}$ & 20651.145 & 121 & 170.670 & \\
\hline Total & 31781.564 & 143 & 222.248 & \\
\hline
\end{tabular}

TEST ON MEANS USING NEWNAN-KEULS PROCEDURE:

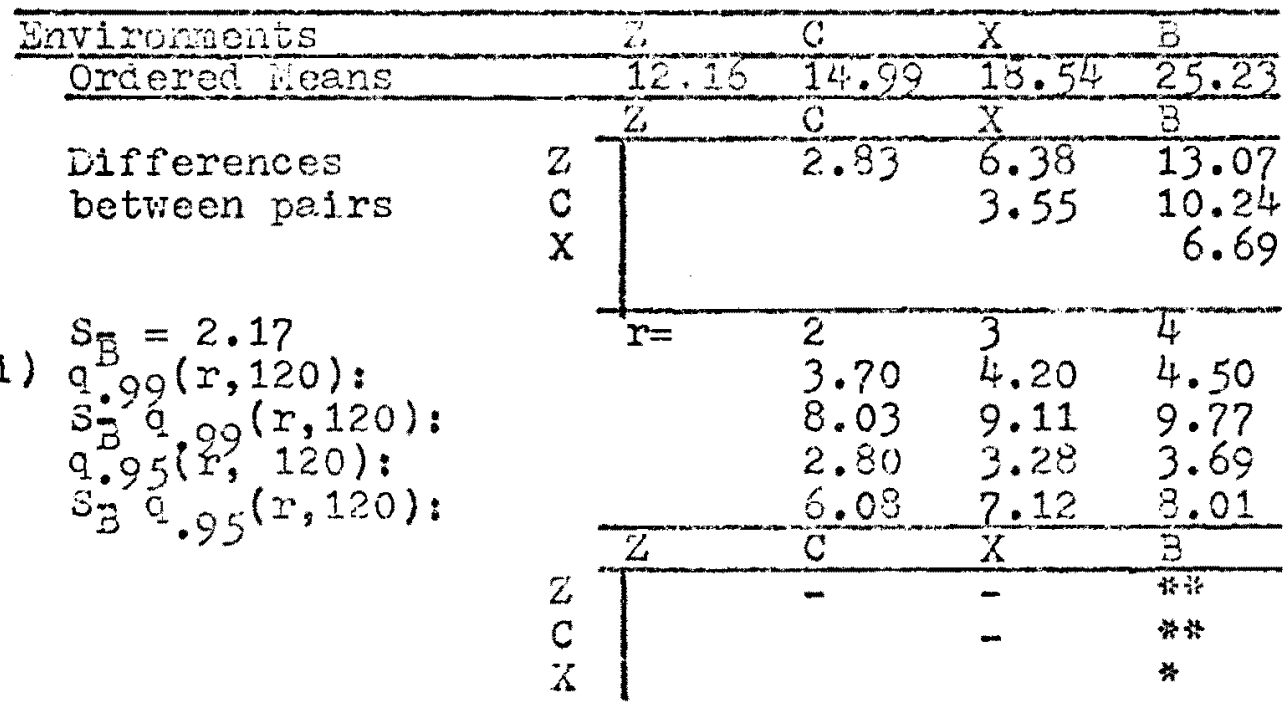


The results of the analysis of variance in part if of Table III lead to the rejection of the nul.I hypothesis at the .01 level of significance since $F_{.99}(3,120)=3.95$. There vere no significant interaction eifects between days and environments on this criterion at the .01 level since $F_{.99}(6,120)=2.96$. The test on means 1 part 111 of Table III shows that the mean frequency of Interaction in envirunment (B) is statistically different from the mean frequency in environments $(X),(C)$, and $(Z)$ since $s_{\bar{B}} q .95(2,120)=6.08, s_{\bar{B}} q .99(3,120)=9.11$, and $S_{\bar{B}} q_{.99}(4,120)=9.77$ respectively. It was noted that the difference in the mean frequency of Interaction between environments $(B)$ and $(X)$ was statistically significant at the .05 level, and the difference in this frequency between environments $(B)$ and $(C)$, and $(B)$ and $(Z)$, was statistically significant at the .01 level. Thus, the alternative hypothesis that the frequency of Interaction would increase as a function of environment (B) and decrease as a function of environinents $(x),(c)$, and $(z)$, was accepted. No other differences were statisticaliy significant.

The fourth major hypothesis was stated as follows:

$\mathrm{H}_{\mathrm{O}}$ : There woula be no aifference in the frequency of Follows in C's Play as a function of environments $(X)$, $(B),(C)$, and $(z)$.

$\mathrm{H}_{1}$ : There would be an increase in the frequency of Follows in $C^{\prime}$ 's Play as a function of environment $(R)$ and a decrease in this frequenoy as a function of environment. $(x)$.

Table IV includes an AB Sumary of the Observed Lata, Analysis 'of Veriance, End a Test on Neans Using Yenran-Keuls Procedure 
on Follows in C's Play.

TABLE IV

AB SUMMARY OF OBSERVED DATA, ANALYSIS OF VARIANCE, AND TEST ON MEANS USING NWMMAN-KEULS PROCFIURE ON FOLIOHS IN C''S PLAY

AP SUMLPY OF OBSERVED DATA:

Environments

(i)

\begin{tabular}{ll|l|l|l|l|l}
\hline & $b_{X}$ & $b_{B}$ & $b_{C}$ & $b_{Z}$ & Total \\
\hline$a_{1}$ & 113.4 & 260.6 & 18.5 & 15.7 & 408.2 \\
\hline$a_{2}$ & 155.5 & 218.0 & 7.6 & 0.0 & 381.1 \\
\hline$a_{3}$ & 134.4 & 224.5 & 7.1 & 12.2 & 378.2 \\
\hline
\end{tabular}

ANAIYSIS OF VAPIANCE OF FOLLOWS IN C'S PIAY:

\begin{tabular}{|c|c|c|c|c|}
\hline Source of Variation & $S S$ & $\overline{d F}$ & WS & $\mathrm{E}$ \\
\hline Between $\underline{\underline{H}-\mathrm{C} \text { pairs }}$ & 2698.784 & 11 & 245.344 & \multirow{4}{*}{$\begin{array}{l}.10 \\
52.24 * \\
.50\end{array}$} \\
\hline 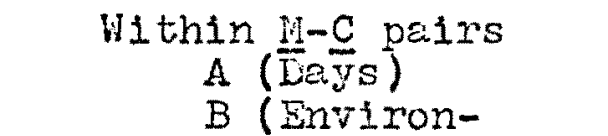 & $\begin{array}{r}15839.388 \\
11.408 \\
8836.586\end{array}$ & $\begin{array}{c}132 \\
2 \\
3\end{array}$ & $\begin{array}{r}119.995 \\
5.704 \\
2945.528\end{array}$ & \\
\hline AXB (Days $x$ & 168.382 & 6 & 28.063 & \\
\hline Restiual (Error) & 6823.012 & 121 & 56.388 & \\
\hline Total & 18538.172 & 143 & 129.637 & \\
\hline
\end{tabular}


TABLE. IV--Continued

TEST ON MEANS USING NEMMAN-KEULS PROCEDURE:

\begin{tabular}{|c|c|c|c|c|c|c|}
\hline & nvironments & & $Z_{2}$ & $\mathrm{C}$ & $x$ & $B$ \\
\hline & Ordered Means & & .26 & .92 & 11.20 & 19.53 \\
\hline & & & 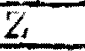 & $\mathrm{C}$ & $x$ & $B$ \\
\hline & Lifferences & $z$ & & .16 & 10.44 & 18.77 \\
\hline & between pairs & C & & & 10.28 & 18.61 \\
\hline (iii) & & & $r$ & 2 & & \\
\hline & $\mathrm{B}_{00}(r, 120)$ & & & 3.70 & 4.20 & 4.50 \\
\hline & $S_{\bar{R}} \mathrm{q} q(\mathrm{r}, 120)$ & & & 5.61 & 6.59 & $8.0 ?$ \\
\hline & & & $\bar{Z}$ & $\mathrm{C}$ & $\mathrm{x}$ & $\mathrm{B}$ \\
\hline & & $z$ & & & ** & \#* \\
\hline & & C & & & ** & \#* \\
\hline & & $\mathrm{x}$ & & & & ** \\
\hline
\end{tabular}

The results of the analysis of variance in part if of Table IV lead to the rejection of the null hypothesis since $F .99$ $(3,120)=3.95$. There were no significant interaction effects between days and environments on this criterion since $F .99$ $(6,120)=2.96$. The test on means in part 111 of Table IV shows that the mean frequency of Follows in C's Play in environment ( $B$ ) was statistically alfferent from environments $(x),(C)$, and $(z)$. The alternative hypothesis that there would be an increase in the frequency of Follows in C's Play as a function of environment ( $B)$, and a decrease in this frequency as a function of environment $(X)$ was accepted at the .01 level of significance.

The fifth major hypothesis was stated as follows:

$\mathrm{H}_{0}$ : There would be no aifference in the frequency of Rewards as a function of the environments $(X),(B)$, $(C)$, and $(Z)$.

$\mathrm{H}_{1}$ : There woula be a difference in the frequency of Rewards as a function of environments $(X),(B),(C)$, and $Z$. 
Table $V$ includes an $A B$ Summary of the Data Observed and an Analysis of Variance of Rewards.

\section{TABLE V}

AB SUMMARY OF OBSERVLD TATA

ANALYSIS OF VARIANCE

ON BETARDS

\section{AB SUMMARY OF OBSERVED DATA:}

Environments

(1)

\begin{tabular}{|c|c|c|c|c|c|}
\hline & $b_{x}$ & $b_{B}$ & ${ }^{b_{C}}$ & $b_{z}$ & Total \\
\hline$a_{1}$ & 5.2 & 4.6 & 3.1 & 6.1 & 19.0 \\
\hline$a_{2}$ & 5.7 & 3.8 & 5.7 & 8.6 & 23.8 \\
\hline$a_{3}$ & 6.8 & 4.7 & 7.4 & 8.7 & 27.6 \\
\hline
\end{tabular}

ANAIYSIS OF VAPIANCE OF REWARDS:

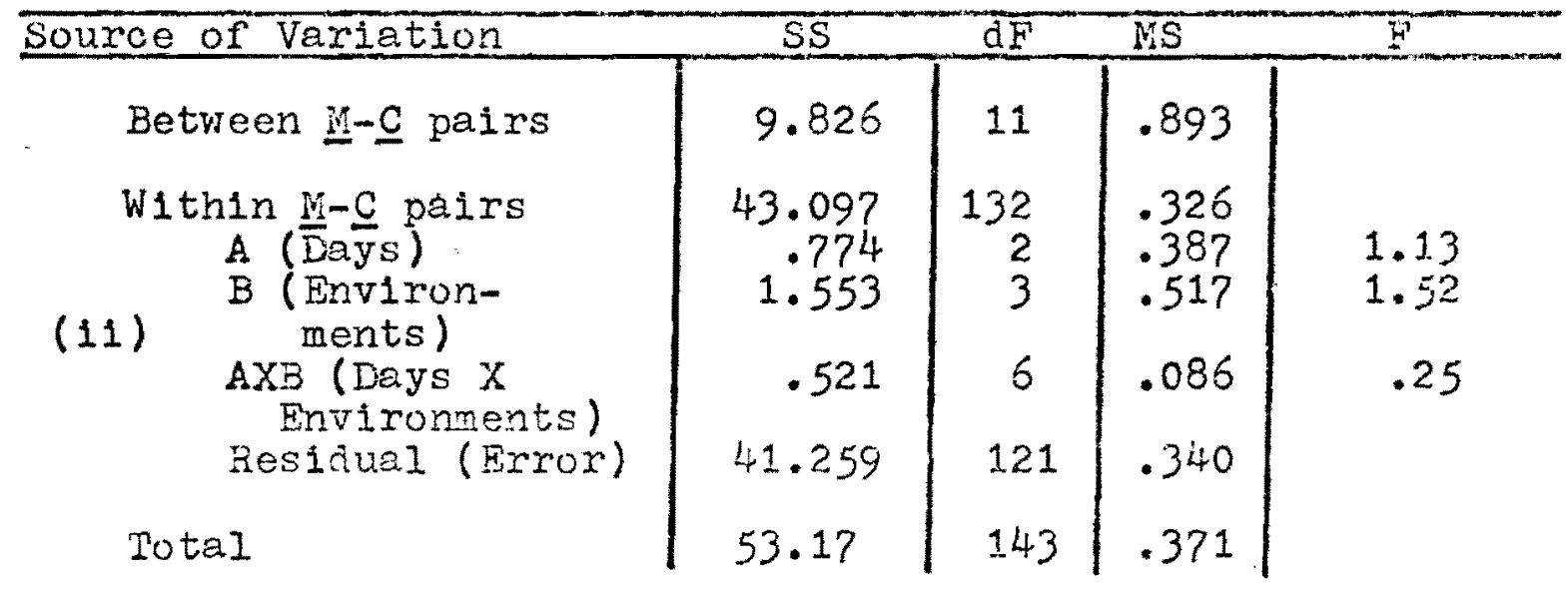

The results of the analysis of variance in part ii of Table $V$ show that there is no significant difference in the frequency of zewaris as a function of the environments $(X),(B),(C)$, and $(z)$ since $F .99(3,120)=3.95$. There vexe no sisnificant , day by enviroment interaction efiects on the frequency of Re- 
wards since $F_{.99}(6,120)=2.96$. The conclusion was that there was no difference in the frequency of Reweris as a function of the environinents $(X),(B),(C)$, and $(Z)$, and the null hypothesis was accepted at the .01 level of significance.

The first supplementary hypothesis was stated as follows:

$\mathrm{H}_{0}$ : There would be no difference in the frequency of Commands as a function of the environments $(X),(B),(C)$, and $(Z)$.

$\mathrm{H}_{1}$ : There would be an increase in the freauency of commands as a function of environments $(C)$ and $(Z)$, and a decrease in thts frequency as a function of environments $(X)$ and $(B)$.

Table VI includes an AB Summary of the Observed Data, Analysis of Vartarce, and a Test on Means Usins the Newman-Keuls Procedure on Commands.

\section{TABLE VI}

AB SUMMARY OF OBSERVED LATA, ANALYSIS OF VARIANCE,

AND TEST ON MEANS USING NENMAN-KBULS

PROCEDURE ON COMIANDS

\section{AB SUMARY OF OBSERVED DATA:}

Environments

(1)

\begin{tabular}{l|l|l|l|l|l|l}
\hline & $b_{x}$ & $b_{B}$ & $b_{C}$ & $b_{z}$ & Total \\
\hline$a_{1}$ & 31.0 & 20.4 & 70.0 & 81.7 & 203.1 \\
\hline$a_{2}$ & 22.5 & 20.6 & 84.1 & 63.0 & 195.3 \\
\hline$a_{3}$ & 17.8 & 19.1 & 75.4 & 73.4 & 185.7 \\
\hline & 71.4 & 60.1 & 229.5 & 223.1 & 584.1
\end{tabular}


TAEIE VI--Continued

ANALYSIS OF VARIANCE OF COMANDS:

\begin{tabular}{|c|c|c|c|c|}
\hline Source of Variation & $\overline{S S}$ & $\mathrm{dF}$ & IS & $F^{2}$ \\
\hline Between $\underline{M-C}$ pairs & 235.439 & 11. & 21.403 & \\
\hline $\begin{array}{l}\text { Within } \frac{\text { M-C pairs }}{A} \text { (Days) } \\
\text { B (i1) Environ- } \\
\text { ments) }\end{array}$ & $\begin{array}{r}1281.136 \\
3.155 \\
718.351\end{array}$ & $\begin{array}{c}132 \\
2 \\
3\end{array}$ & $\begin{array}{r}9.705 \\
1.582 \\
239.450\end{array}$ & $53.77^{* * *}$ \\
\hline $\begin{array}{c}\text { AXB (Days X } \\
\text { Environments) }\end{array}$ & 20.758 & 6 & 3.459 & .78 \\
\hline Residual (Error) & 538.862 & 121 & 4.453 & \\
\hline Total & 1516.575 & 143 & 10.605 & \\
\hline
\end{tabular}

TEST ON MEANS USTNG NEWMAN-KEULS PROCEDURE:

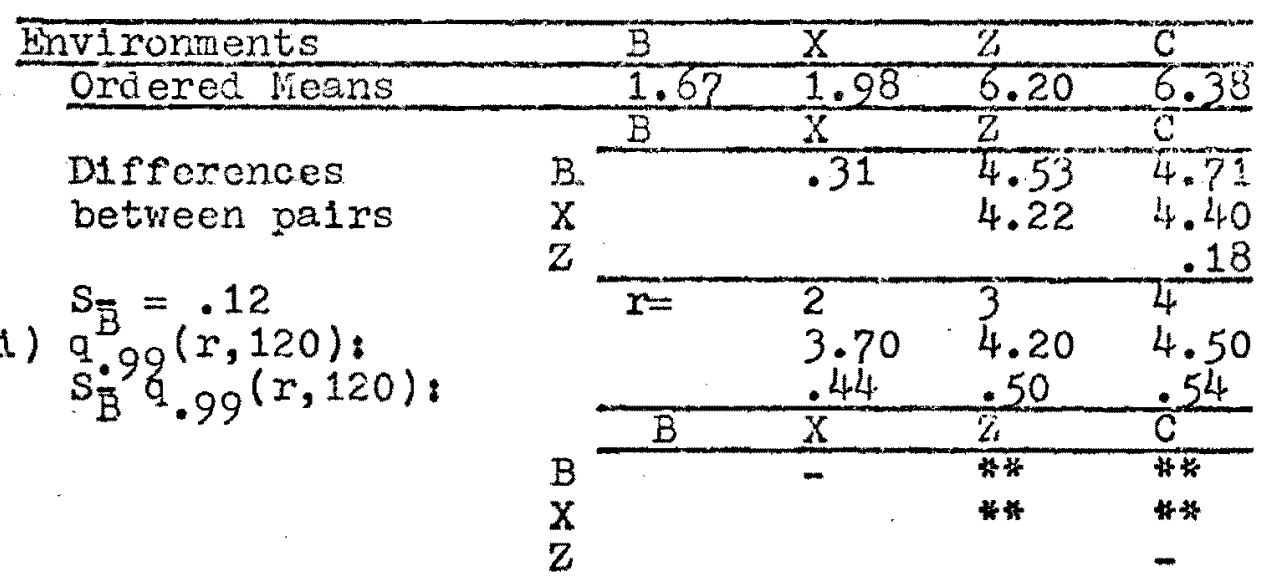

The results of the analysis of variance in part il of Table VI lead to the rejection of the null hypothesis since $F .99$ $(3,120)=3.95$. There were no significant interaction effects between days and environments on this criterion since F.99 $(6,120)=2.96$. The test on weans in part i1i of Table VI shows thet the mean frequency of Commands in environment (C) was sisnificently different from the wean frecuency in environments (B) and ( $X)$. The mean frequenoy of Commands in environment 
(2) was statistically different from the mean frequency in environments $(X)$ and $(B)$, Thus, the alternative hypothesis that there vould be an increase in the frequency of Commands as a function of environments $(C)$ and $(Z)$, and a decrease in this frequency as a function of environments $(X)$ and $(B)$, was accepted at the .01 level of significance.

The second supplementary hypothesis was stated as follows:

$\mathrm{H}_{0}$ : There would be no difference in the frequency of Complies as a function of environiments $(X),(B),(C)$, and $(Z)$.

$\mathrm{H}_{1}$ : There would be an increase in the frequency of Complies as a function of environments (C) and (Z), and a decrease in this frequency as a function of environments $(X)$ and $(B)$.

Table VII includes an AB Summary of Observed Data, Anajysis of Variance, and a Test on Means Using Newman-Keuls Procedure on Complies.

\section{TABLE VII}

AB SUMMARY OF OBSERVED DATA, ANALYSIS OF VARIANCE, AND TEST ON YEANS USING NEWMAN-KEUIS PROCEDURE ON COMPLIES

\section{AB SUMARY OF ODSERVED DATA:}

Environments

(1)

\begin{tabular}{ll|l|l|l|l|l}
\hline & $b_{X}$ & $b_{B}$ & $b_{C}$ & $b_{Z}$ & Total \\
\cline { 2 - 6 } & $a_{1}$ & 10.4 & 3.7 & 15.8 & 19.9 & 50.8 \\
\cline { 2 - 6 } & $a_{2}$ & 7.4 & 2.4 & 19.2 & 23.0 & 37.0 \\
\hline & $a_{3}$ & 7.6 & 3.7 & 21.2 & 28.7 & 61.7 \\
\cline { 2 - 6 } & & 25.4 & 14.8 & 52.7 & 71.6 & 169.5 \\
\hline
\end{tabular}


TABLE VII--Continued

\section{ANALYSIS OF VARIANCE OF COMPIIES:}

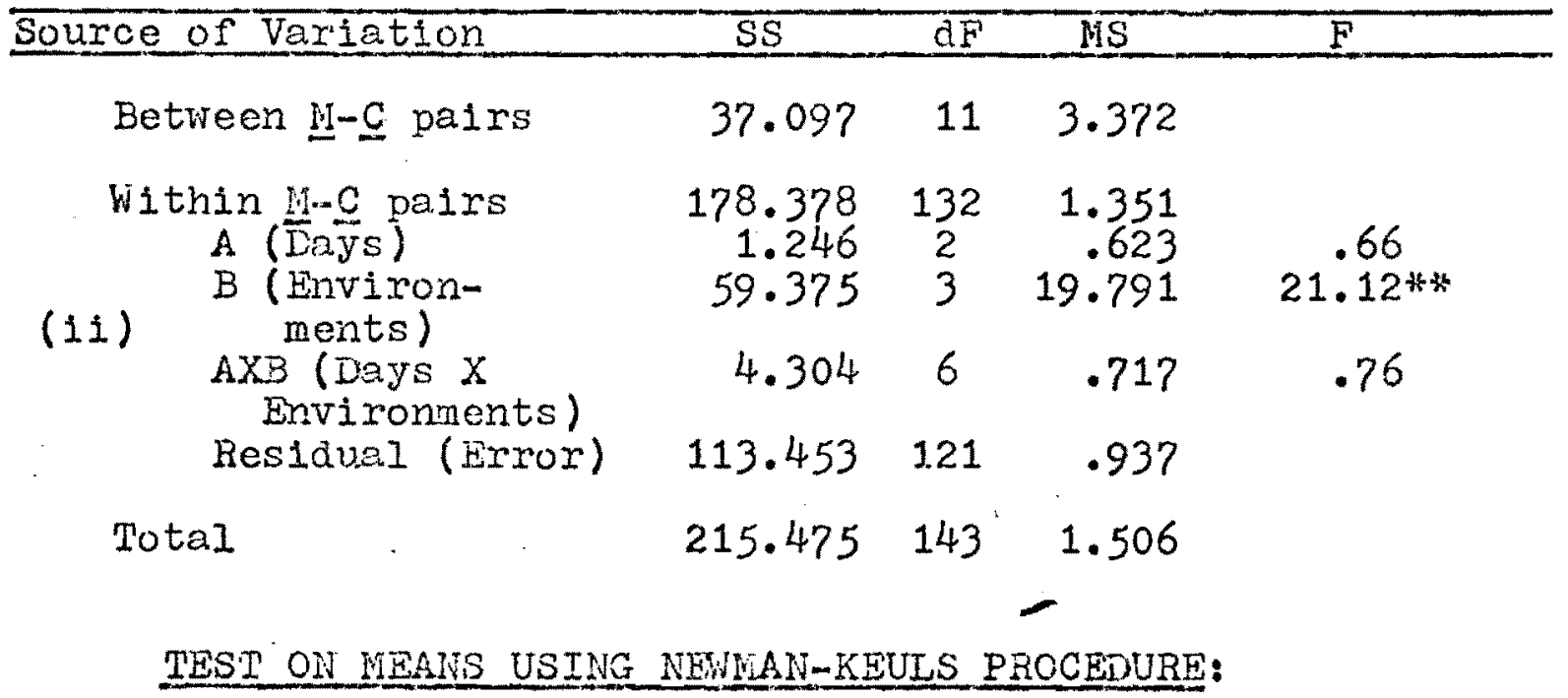

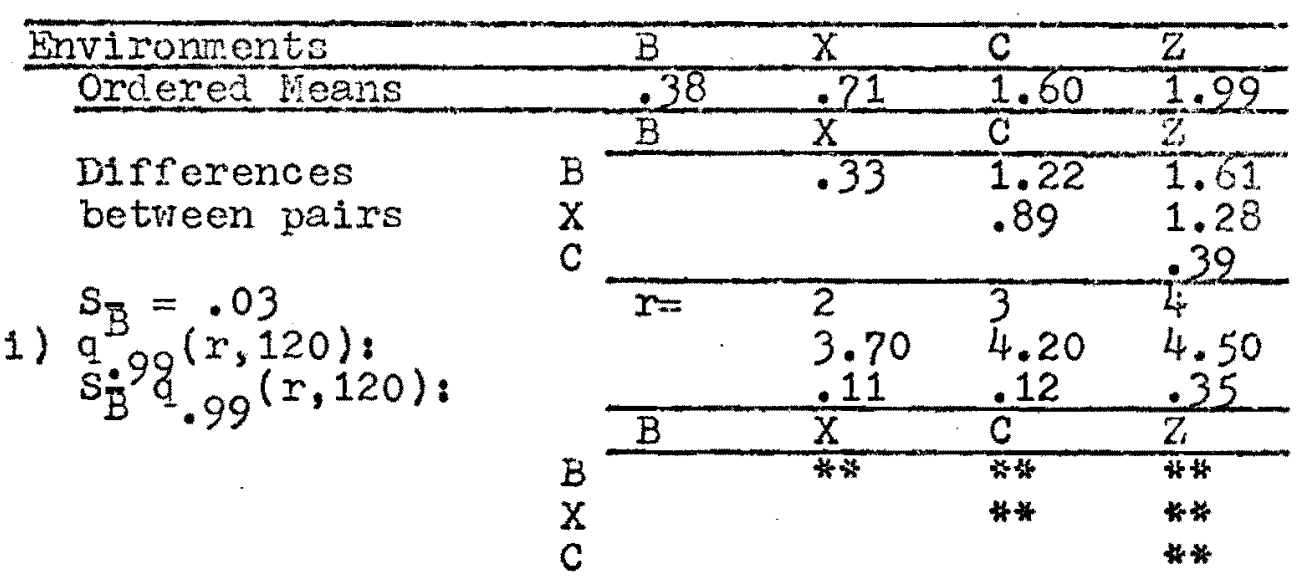

The results of the analysis of variance in part il of Table VII lead to the rejection of the null hypothesis since $F .99$ $(3,120)=3.95$. There were no sisnificant day by environment interaction effects since $F_{.99}(6,120)=2.96$. The test on means shows that the mean frequency of complies in environment $(Z)$ was statistically disferent from the mean frequency in environments $(B),(X)$, and $(C)$ at the .01 levels since $S_{B} q .99^{(4,}$

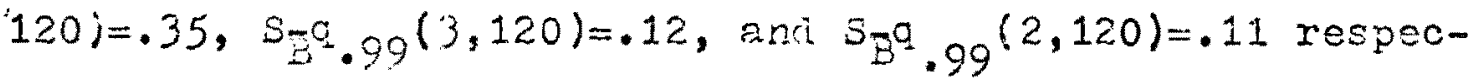


tively. The mean frequency of Complies in Environment (C) was statistically different from the mean frequency in environments $(B)$ and $(X)$ at the .01 level since $S_{B} q .99(3,120)=.12$ and $S_{\bar{B}} q .99(2,120)=.11$ respectively. The mean frequency of Complies in environment $(X)$ was statistically different from the mean frequency in envirorment $(B)$ at the .01 level since $S_{E^{q}} .99$ $(2,120)=.11$. Thus, the alternative hypothesis that there would be an increase in the frequency of Complies as a function of environments $(C)$ and $(Z)$, and a decrease in this frequency as a function of environments $(X)$ and $(B)$, was accepted at the .01 level of significance.

The third supplementary hypothesis was stated as follows:

$\mathrm{H}_{0}$ : There would be no difference in the frequency of Asks Questions as a function of environments $(X),(B),(C)$, and $(Z)$.

$\mathrm{H}_{1}$ : There would be an increase in the frequency of Asks Questions as a function of environment (B), and a decrease in this frequency as a function of environments $(X),(C)$, and $(Z)$.

Table VIII includes an AB Sumary of Observed Lata, Analysis of Varlance, and a Test on Means Using Newman-Keuls Procedure on Asks Questions.

\section{TABLE VIII}

AB SUMARY OF OBSERVED DATA, ANALYSIS OF VARIANCE, AND TEST ON MFANS USING NEHLAN-KEULS PROCENURE OR ASKS QUESTIORS 
TABIE VIII-..Continued

AB SUIIABY OF OBSERVED DATA;

Environments

(1)

\begin{tabular}{l|l|l|l|l|l}
\hline & $b_{x}$ & $b_{3}$ & $b_{c}$ & $b_{z}$ & TotaI \\
\hline$a_{1}$ & 24.6 & 36.5 & 25.6 & 16.5 & 103.2 \\
\hline$a_{2}$ & 14.5 & 29.4 & 18.5 & 7.2 & 69.6 \\
\hline$a_{3}$ & 16.2 & 21.5 & 18.3 & 13.4 & 69.4 \\
\hline & 55.3 & 87.4 & 62.4 & 37.1 &
\end{tabular}

ANALYSIS OF VARTALCE OF ASKS QUESTIONS:

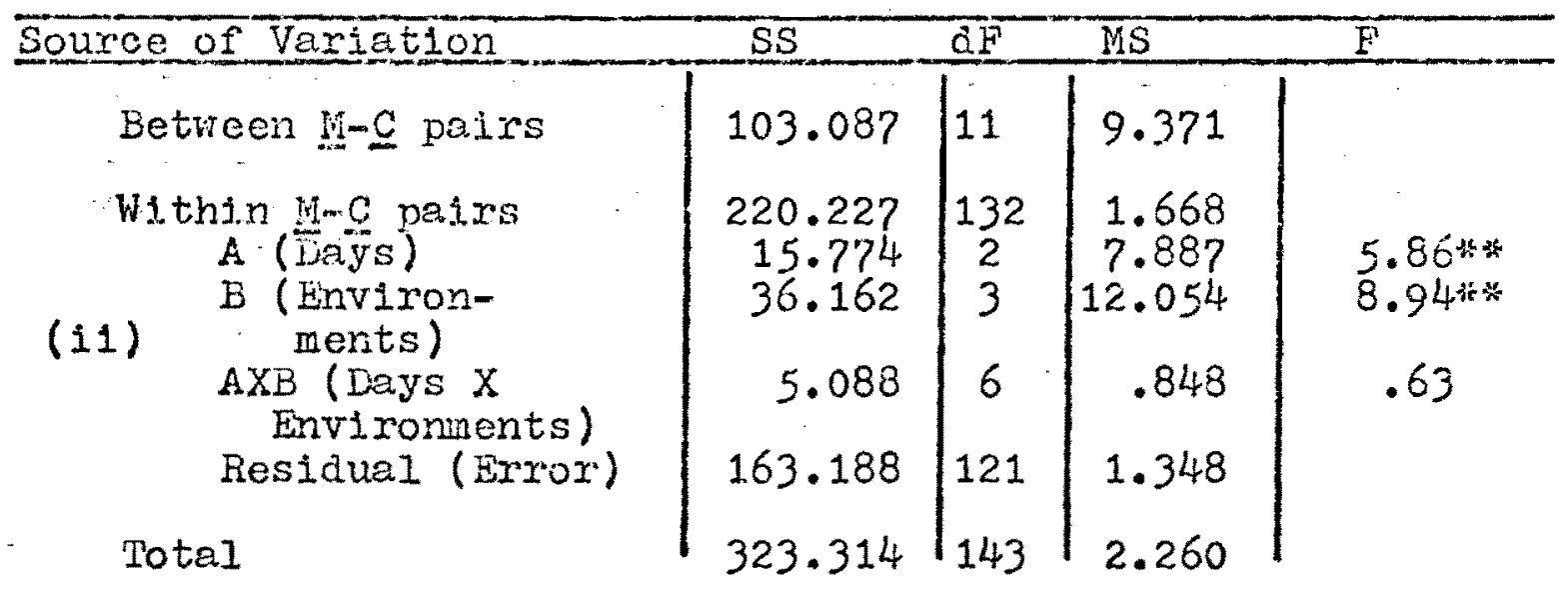

TEST ON HEANS USING NEUMAN-KEULS PROCEDURE:

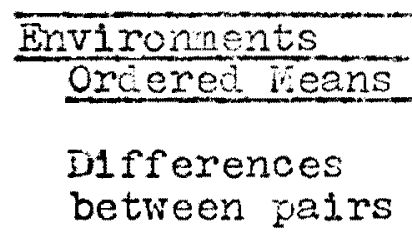

(iii) $S_{\bar{B}}=.04$

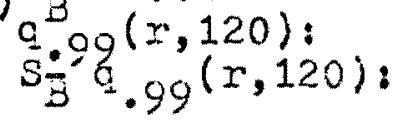

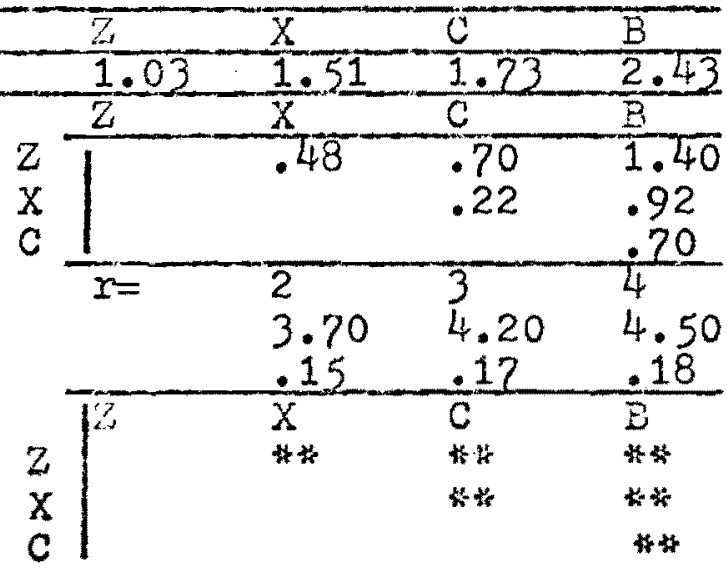


The results of the analysis of variance in part il of Table VIII lead to the rejection of the null hypothesis at the .01 level of signiflcance since $F \cdot 99(3,120)=3.95$. There were no significant day by environment interaction effects on this criterion since $F_{.99}(6,120)=2.96$. However, the variance due to days was significant at the .01 level since $F_{.99}(2,120)=$ 4.79. A close look at the data in the $A B$ Summary in part 1 of Pable VIII shows that the frequency of Asks Questions was higher on cay (1) than on days (2) and (3). The test on means in part 11i of Table VIII shows that the mean frequency of Asks Questions in environment (B) was statistically different than the mean frequency in environments $(C),(X)$, and $(Z)$ at the .01 level since $S_{\bar{B}} q .99(2,120)=.15, S_{\bar{B}^{q}} \cdot .99(3,120)=.17$, and $\mathrm{S}_{\bar{B}} \mathrm{a} .99(4,120)=.18$ respectively. The mean frequency of Asks Questions in environment (C) was statistically different from the mean frequency in environments $(X)$ and $(Z)$ at the .01 level since $s_{B}^{-q} \cdot 99(2,120)=.15$ and $s_{B} q .99(3,120)=.17$ respectively. The mean frequency of Asks Questions in environment $(x)$ was statistically different from the mean frequency in enviroment $(Z)$ at the .01 level since $S_{\bar{B}} G_{.99}(2,120)=.15$. Thus, the alternative hypothesis that there rould be an increase in the frequency of Asks questions as a function of environment ( 3 ), and a decrease in this irequency as a func.tion of environments $(X),(C)$, and $(z)$ was accepter at the .01 level of significance.

Cne question not answered by the foregoing research and 
statistical analysis was whether the order of presentation of environments had a significant effect on the frequency of criteria measures. It was mentioned previously that the design of this experiment and the restraints of the clinical situation dictated that the logical order of free-time environment $(X)$ and clean-up environment $(Z)$ were flrst and last respectively. However, the design attempted to counterbalance and randomize the sequential order of child's game and rules, environment (B), and mother's game and rules, environment (C). The counterbalancinశ్ involved an $\mathrm{XBCZ}, \mathrm{XCBZ}, \mathrm{XBCZ}$ sequential order for four $\underline{N}-\underline{C}$ pairs and an XCBZ, XBCZ, XCBZ sequential order for four other $\underline{M}-\underline{C}$ pairs over the three days of baselire sessions. Groups were organized for the comparison of frequencies of criteria measures in the same environments placed differently in the sequential order of presentation. Specifically, group $B_{1}$ included data in environment (B) presented after environment $(X)$ and before environments $(C)$ and $(Z)$. Group $B_{2}$ included data in environment (B) presented after environments $(X)$ and $(C)$ and before environment (2). Group $C_{1}$ included data in environinent (C) presented after environment $(X)$ and before environments $(B)$ and $(Z)$. Group $z_{1}$ included data in environment $(Z)$ following the XBC order of presentation. Group $z_{2}$ included data in environment (2) following the XCB order of presentation. There were four Ii-C pairs presented each of the counterbalanced sequential orders over three days of data cullection which provided 12 
observations on each of the eight criteria behaviors in each of the groups described above. Since there were no significant day by environment interaction effects at the .01 level of significance on any of the elght criteria behaviors, a $t$-test statistic was used to cornpare the mean frequencies of criteria measures between the groups.

Table IX includes Comparisons of the llean Frequencies of the Eight Criteria Measures between Groups $B_{1}$ and $B_{2}$. The null hypothesis that there would be no difference in the frequency of criteria measures between Groups $B_{1}$ and $B_{2}$ was tested at the .05 level of significance. The .05 level of significance was used since the probability of rejectins the null hypothesis when it was true was considered a more costly error than accetirg it when it was faise. The decision rules for rejecting the null hypothesis were siated as follows: Reject the null hypothesis when $t_{\text {OBS }}<t .025(22)=-2.0$ ? or $>t_{.975}(22)=2.07$. Do not reject the null hypothesis otherwise. 
TABLE IX

COMPARISON OF THE MEAN FREQUENCIES OF

THE EIGHT CRITERIA BEHAVIORS

BE'TWEEN GROUPS $B_{1}$ AND $B_{2}$

\begin{tabular}{|c|c|c|c|c|c|}
\hline Criteria & Ehvironments & Means & Variances & $t_{O B S}$ & Decision \\
\hline \multirow[t]{2}{*}{ Rewards } & $B_{1}$ & .19 & .47 & \multirow{2}{*}{1.50} & \multirow{2}{*}{$\begin{array}{l}\text { Do not } \\
\text { reject } \\
\mathrm{H}_{0}\end{array}$} \\
\hline & $B_{2}$ & .04 & .20 & & \\
\hline \multirow[t]{2}{*}{ Commends } & $B_{1}$ & 1.42 & 1.45 & \multirow{2}{*}{-.92} & \multirow{2}{*}{$\begin{array}{l}\text { Do not } \\
\text { reject } \\
\mathrm{H}_{0}\end{array}$} \\
\hline & $B_{2}$ & 1.75 & 2.90 & & \\
\hline \multirow{2}{*}{$\begin{array}{l}\text { Follows in } \\
\text { C's play }\end{array}$} & $B_{1}$ & 25.70 & 288.20 & \multirow{2}{*}{$\cdot 30$} & \multirow{2}{*}{$\begin{array}{l}\text { Do not } \\
\text { reject } \\
\mathrm{H}_{0}\end{array}$} \\
\hline & $B_{2}$ & 20.78 & 242.26 & & \\
\hline \multirow{2}{*}{$\begin{array}{l}\text { Gives Up } \\
\text { Control. }\end{array}$} & $B_{1}$ & .37 & 1.80 & \multirow{2}{*}{-.87} & \multirow{2}{*}{$\begin{array}{l}\text { Do not } \\
\text { reject } \\
\mathrm{K}_{0}\end{array}$} \\
\hline & $B_{2}$ & 3.12 & 119.25 & & \\
\hline \multirow{2}{*}{$\begin{array}{l}\text { Asks } \\
\text { Questions }\end{array}$} & $B_{1}$ & 1.75 & 4.91 & \multirow{2}{*}{-.39} & \multirow{2}{*}{$\begin{array}{l}\text { Do not } \\
\text { reject } \\
\mathrm{H}_{0}\end{array}$} \\
\hline & $\mathrm{B}_{2}$ & 2.12 & 6.22 & & \\
\hline \multirow[t]{2}{*}{ Interaction } & $B_{1}$ & 25.80 & 239.75 & \multirow{2}{*}{.54} & \multirow{2}{*}{$\begin{array}{l}\text { Do not } \\
\text { reject } \\
\text { Fo }\end{array}$} \\
\hline & $B_{2}$ & 22.33 & 231.58 & & \\
\hline \multirow{2}{*}{$\begin{array}{l}\text { Independent } \\
\text { Play }\end{array}$} & $B_{1}$ & 9.20 & 97.64 & \multirow{2}{*}{.85} & \multirow{2}{*}{$\begin{array}{l}\text { Do not } \\
\text { rejeot } \\
\text { Ho }\end{array}$} \\
\hline & $B_{2}$ & 6.35 & 38.65 & & \\
\hline \multirow[t]{2}{*}{ Conplies } & $B_{1}$ & .37 & .60 & \multirow{2}{*}{-1.07} & \multirow{2}{*}{$\begin{array}{l}\text { Do not } \\
\text { reject } \\
\mathrm{H}_{0}\end{array}$} \\
\hline & $B_{2}$ & .40 & .39 & & \\
\hline
\end{tabular}


The data analysis in Table IX shows that there was no significant aifference in the mean frequencies of any of the elght criteria behaviors between Groups $B_{1}$ and $B_{2}$ at the .05 level of significance. The conclusion was that the order of presentation had no significant effect on the frequency of criteria measures in environment (B).

Table $X$ includes Comparisons of Mean Frequencies of the Eight Criteria Measures between Groups $C_{1}$ and $C_{2}$. A twotailed t-test was used to test the null hypothesis that there would be no difrerence in the mean frequency of the elght criteria measures between Groups $C_{1}$ and $\bar{C}_{2}$ at the .05 level of significance. The decision rules concerning the nul.? hypothesis were stated as follows: Reject the null hypothesis when $t_{\text {OBS }}\left\langle t_{.025}(22)=-2.07\right.$ or $\rangle t_{.975}(22)=2.07$. Do not reject the null hypothesis otherwise. 
TABLE X

COMPARISONS OF THE MEAN FRERUENCIES OF

THE EIGET CKITERIA BEHAVIORS

BETWEEN GROUPS $C_{1}$ AND $C_{2}$

\begin{tabular}{|c|c|c|c|c|c|}
\hline Criteria & Environments & Heans & Variances & $t_{\text {OBS }}$ & Decision \\
\hline \multirow[t]{2}{*}{ Rewards } & $c_{1}$ & .53 & .15 & \multirow{2}{*}{1.29} & \multirow{2}{*}{$\begin{array}{l}\text { Do not } \\
\text { reject } \\
\mathrm{H}_{0}\end{array}$} \\
\hline & $c_{2}$ & .35 & .10 & & \\
\hline \multirow[t]{2}{*}{ Commands } & $c_{1}$ & 6.11 & 4.51 & \multirow{2}{*}{-1.49} & \multirow{2}{*}{$\begin{array}{l}\text { Do not } \\
\text { reject } \\
\mathrm{H}_{0}\end{array}$} \\
\hline & $c_{2}$ & 7.05 & $3.88-$ & & \\
\hline \multirow{2}{*}{$\begin{array}{l}\text { Follows in } \\
\text { c's Play }\end{array}$} & $c_{1}$ & 1.90 & 23.54 & \multirow{2}{*}{1.21} & \multirow{2}{*}{$\begin{array}{c}\text { Do not } \\
\text { reject } \\
\mathrm{H}_{0}\end{array}$} \\
\hline & $c_{2}$ & .21 & $\cdot 51$ & & \\
\hline \multirow{2}{*}{$\begin{array}{l}\text { Gives Up } \\
\text { Control }\end{array}$} & $c_{1}$ & 11.90 & 127.33 & \multirow{2}{*}{-1.55} & \multirow{2}{*}{$\begin{array}{l}\text { Do not } \\
\text { reject } \\
\mathrm{H}_{0}\end{array}$} \\
\hline & $c_{2}$ & 18.31 & 186.90 & & \\
\hline \multirow[t]{2}{*}{$\begin{array}{l}\text { Asks } \\
\text { Questions }\end{array}$} & $c_{1}$ & 1.28 & 1.43 & \multirow{2}{*}{-1.14} & \multirow{2}{*}{$\begin{array}{l}\text { Do not } \\
\text { reject } \\
\mathrm{H}_{0}\end{array}$} \\
\hline & $c_{2}$ & 1.86 & 1.71 & & \\
\hline \multirow[t]{2}{*}{ Interaction } & $c_{1}$ & 13.03 & 201.68 & \multirow{2}{*}{.92} & \multirow{2}{*}{$\begin{array}{l}\text { Do not } \\
\text { reject } \\
\mathrm{H}_{0}\end{array}$} \\
\hline & $\mathrm{C}_{2}$ & 8.05 & 63.20 & & \\
\hline \multirow[t]{2}{*}{$\begin{array}{l}\text { Independent } \\
\text { Play }\end{array}$} & $C_{1}$ & 5.40 & 125.85 & \multirow{2}{*}{.51} & \multirow{2}{*}{$\begin{array}{l}\text { Do not } \\
\text { reject } \\
\mathrm{H}_{0}\end{array}$} \\
\hline & $\mathrm{c}_{2}$ & 3.62 & $17 \cdot 59$ & & \\
\hline \multirow[t]{2}{*}{ Complies } & $c_{1}$ & 2.17 & .96 & \multirow{2}{*}{1.34} & \multirow{2}{*}{$\begin{array}{c}\text { Do not } \\
\text { reject } \\
\mathrm{H}_{0}\end{array}$} \\
\hline & $c_{2}$ & 1.52 & 1.10 & & \\
\hline
\end{tabular}


The data analysis in Table $X$ shows that there were no significant differences in the mean frequencies of the eight criteria behaviors between Groups $c_{1}$ and $c_{2}$ at the .05 level of significance. The conclusion was that the order of presentation of environments had no significant effect on the frequency of criteria behaviors in environment (c).

Table XI includes Comparisons of Mean Frequencies of the Eight Criteria Behaviors between Groups $z_{1}$ and $z_{2} \cdot A$ two-ta1led t-test was used to test the null hypothesis that there would be no difference in the mean frequency of the eight criteria measures between Groups $z_{1}$ and $z_{2}$ at the .05 level of significance. The decision rules concerning the null hypothesis were stated as follows: Reject the null hy-

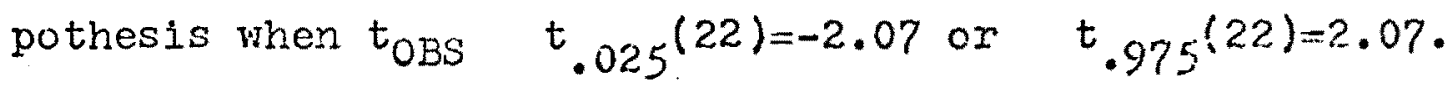
Do not reject the null hypothesis otherwise. 
TABLE XI

COMPARTSON OF THE MEAN FREQUENCIES OF

THE EIGHT CRITEEIA BEHAVIORS

BEIVEEN GROUPS $z_{1}$ AND $z_{2}$

\begin{tabular}{|c|c|c|c|c|c|}
\hline Criteria & Environments & lieans & Variances & $t_{O B S}$ & Decision \\
\hline Rewards & $\begin{array}{l}z_{1} \\
z_{2}\end{array}$ & $\begin{array}{l}.60 \\
.52\end{array}$ & $\begin{array}{l}.94 \\
.40\end{array}$ & .73 & $\begin{array}{l}\text { Do not } \\
\text { reject } \\
\mathrm{h}_{0}\end{array}$ \\
\hline Commands & $\begin{array}{l}z_{1} \\
z_{2}\end{array}$ & $\begin{array}{l}6.81 \\
6.06\end{array}$ & $\begin{array}{l}17.21 \\
10.60\end{array}$ & .43 & $\begin{array}{l}\text { Do not } \\
\text { reject } \\
\mathrm{H}_{0}\end{array}$ \\
\hline $\begin{array}{l}\text { Follows in } \\
\text { C's Play }\end{array}$ & $\begin{array}{l}z_{1} \\
z_{2}\end{array}$ & $\begin{array}{l}.63 \\
.39\end{array}$ & $\begin{array}{l}4.69 \\
.17\end{array}$ & .38 & $\begin{array}{c}\text { Do not } \\
\text { reject } \\
\mathrm{H}_{0}\end{array}$ \\
\hline $\begin{array}{l}\text { Gives Up } \\
\text { Control }\end{array}$ & $\begin{array}{l}z_{1} \\
z_{2}\end{array}$ & $\begin{array}{l}16.57 \\
16.05\end{array}$ & $\begin{array}{l}227.89 \\
386.35\end{array}$ & .07 & $\begin{array}{l}\text { Do not } \\
\text { reject } \\
\mathrm{H}_{0}\end{array}$ \\
\hline $\begin{array}{l}\text { Asks } \\
\text { Questions }\end{array}$ & $\begin{array}{l}z_{1} \\
z_{2}\end{array}$ & $\begin{array}{l}.77 \\
.50\end{array}$ & $\begin{array}{l}.57 \\
7.67\end{array}$ & .33 & $\begin{array}{l}\text { Do not } \\
\text { reject } \\
\mathrm{H}_{0}\end{array}$ \\
\hline Interactior & $\begin{array}{l}z_{1} \\
z_{2}\end{array}$ & $\begin{array}{l}3.57 \\
11.65\end{array}$ & $\begin{array}{l}112.51 \\
320.01\end{array}$ & -1.34 & $\begin{array}{l}\text { Do not } \\
\text { reject } \\
\mathrm{H}_{0}\end{array}$ \\
\hline $\begin{array}{l}\text { Independent } \\
\text { Play }\end{array}$ & $\begin{array}{l}z_{1} \\
z_{2}\end{array}$ & $\begin{array}{l}4.97 \\
5.09\end{array}$ & $\begin{array}{l}48.59 \\
143.31\end{array}$ & -.03 & $\begin{array}{l}\text { Do not } \\
\text { reject } \\
\mathrm{H}_{0}\end{array}$ \\
\hline Complies & $\begin{array}{l}z_{1} \\
z_{2}\end{array}$ & $\begin{array}{l}1.97 \\
2.69\end{array}$ & $\begin{array}{l}2.12 \\
3.70\end{array}$ & -1.03 & $\begin{array}{l}\text { Do not } \\
\text { reject } \\
\mathrm{H}_{0}\end{array}$ \\
\hline
\end{tabular}


The data analysis in Table XI shows that there were no significant differences in the mean frequencles of the elght criteria behaviors between Groups $z_{1}$ and $z_{2}$ at the .05 level of significance. The conclusion was that the order of presentation of environments had no significant effect on the frequency of criteria behaviors in environment $(z)$.

In view of the overall results, it was concluded that standard laboratory environments have a differential effect on the frequency of a broad classs of behaviors which were selected for their facility to delineate interaction difficulties. liore specifically, it was concluded that: 1) The frequency of Interaction, Follows in C's Play and Asks Questions increased as a function of environment $(B)$ and decreased as a function of environments $(X),(C)$, and $(Z)$; 2) The frequency of Gives Up Control, Commands, and Complies increased as a function of environments $(C)$ and $(Z)$ and decreased as a function of environments (X) and (B); 3) The frequency of Independent Play increased as a function of environment $(X)$ and decreased as a function of environments (B), (C), and (Z); 4 ) There was no difference in the Irequency of Rewards as a function of the environments $(X),(B),(C)$, and $(Z)$. The results Indicate that all behaviors excluding Independent play and Rewards, decreased as a function of environment $(X)$ and increased in the functional. way noted above. In general, it was concluaed that the use or environmental control is effective in increasing the probability and occurrence of a broad class of 
problem behaviors in $\mathrm{M}-\mathrm{C}$ interaction. 


\section{DISCUSSION}

This research investigated the effectiveness of using standard laboratory environnents in the application of behavior modification techniques to $\underline{-}-\underline{C}$ interaction difficulties. In the Introduction, it was noted that the aisadvantages of carrying out behavior modification programs in the home included: 1) the presence of an observer changes the home environment, 2) relevant signaling devices force the parent to be at a certain vantage point, and 3) the restraints of recording techniques do not allow observation usually of serious behaviors that occur rarely. It was also noted that the disadvantages of employing behavior modification techniques in the clinical laboratory included: 1) reduction of the Eeneralization of treatment effects across settings, 2) removal of relevant uncontrolled variables present in the home environcent, 3) lack of a reliable methodology for reproducing those situations which stimulate behaviors of concern to therapist and parent alike. When Hanf (1968) empirically derlved a set of stendard laboratory environments (considered to be analogs of those natural environments in which $1-C$ interaction difficulties occurrea), the contention was that the use of these environments would expedite the behavior modification process by providing the environmental stimuli that produce problem behaviors. 
The conclusions of this experiment supported the contention that the use of standard laboratory environments increases the probability and frequency of occurrence of a broad class of problem behaviors across $M-C$ pairs, and facilitates the baseline data collection process. These fjndings imply that the advantages of using behavior modification programs in the home and in the laboratory could be capitalized by the employment of laboratory analogs of those natural environments that produce problem behaviors. These advantages include: 1) generalization of treatment effects across settings, 2) accurate and reliable observation, 3) necessary conditions for within and between dyad comparisons, 4) standardized conditions for replication and stuay of beharioral sequences and their development over time, 5) expedition of the behavior modification process by providing the envixonmental stimuli that produce the problem behaviors, 6) experimental analysis of human behavior by use of standardized environments, and 7) control of irrelevant contaminating variables.

The linitations of the experimental findings were pronounced by the restraints of the clinical situation. The 10sical order of free-time enviroment $(X)$ and clean-up exvironnent ( $Z$ ) occurring firet and last respectively in the sequential order of presentation pronioltei a completely randowized or totally counterceleneci design. Fovever, the data analysis ald not support tre consloeration that orcer efiects vere sinficant in increasine or decreesing the frequency of 
criteria behaviors in a particular environuent. Since the 10gistics of environments mother's game and rules (C) and cleanup (Z) implied that they were similar in respects to providing a mother-control sjtuation, environment (Z) could possibly have been omitted from the date analysis. Then a restructuring of free-time entironment $(x)$, in order to allow variable placement in the sequential order, would have facilitated randomizing or counterbalancing order.

One aspect of the standiard laboratory environments which limited their meeting the criteria of functionally equivalent exemplars of the natural environments of focus was the omission of stimuli frequently present in the latter that may function to affect the frequency of problem behaviors. For example, these stimuli would include telephone interruptions, television, radio, and other distractions. However, the characteiistics of the standard laboratory environments appeared to reproduce those situations which stimulated behavior responses that defined $\mathbb{M}-\underline{C}$ interaction difficulties and would become the focus of ruture behavior modification techniques. 


\section{SUMMARY AND CONCLUSIONS}

This experiment was designed to test the effectiveness of using standard laboratory environments in producing a broad class of problem behaviors which defined interaction difficulties across $\mathbb{M}-\mathbf{C}$ paixs. The effects of four environments, freetime $(X)$, child's game and rules (B), mother's game and rules $(c)$, and clean-up ( $z$ ), on the frequency of eight criteria behavioxs were tested on $12 \underline{\underline{H}}-\underline{C}$ pairs over three days of baseline data collection. It was predicted that the frequency of problem behaviors would increase as a function of environinents $(B),(C)$, and $(Z)$, and decrease as a function of environment $(x)$. In Eeneral, the data analyses confirmed the prediction. Specifically, it was concluded that the frequency of Interaction, Follows in $\mathrm{C}^{\prime} \mathrm{s}$ Play, and Asks Questions increased as a function of environment $(B)$ and decreased as a function of environments $(X),(C)$, and $(Z)$ since the Newan-Keuls test showed statistical difference at the .01 level of significance. The frequency of Gives Up Control, Commands, and Complies increased as a function of environmerts $(C)$ and $(Z)$ and decreasec. as a function of environnents $(X)$ and $(B)$ since the NewmanKeuls test shored statistical difference at the .01 level of significance. The frequercy of Incependent tiay increased as

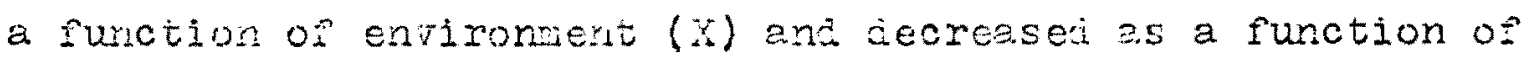
environients (E), (O), end (Z). There was a statistical aif- 
ference in the frequency of Revards as a function of environments $(B),(C)$, and $(Z)$. These results indicate that all behaviors excluding Independent Play and Rewards decreased as a function of environment $(X)$ and increased in the other environments in the functional way noted. It was also noted that the frequency of Rewards was very low since they occurred on the average of less than once every two minutes. The low frequency of this behavior is generally expected in baseline data of $\mathbb{N}-\mathrm{C}$ interaction difficulties. It was interesting to observe that the low frequency of Rewards was consistent in all environments. This was also expected since the lack of rewarding behavior appeared to be predictive of interaction difficulties. Also noted was the fact that Independent Play, the frequency of which increased as a function of environment $(X)$, is by definition mutually exclusive of Interaction. It was concluded that environments $(B),(C)$, and $(Z)$ functioned to increase the probability and frequency of occurrence of a broad class of problem behaviors whereas environment $(X)$ did not.

In general, it was concluded that the use of environmental control was effective in increasing the frequency of problem behaviors and that this methodology is effective in the expedition of the behavior modification process since it provides the environmental stimuli that produces the problem behaviors of focus for modification techniques. 


\section{BIBLIOGEFPTY}

Allen, K. E., Hart, B., Euell, J. S., Harris, F. R. and Wolf, H. M. "Effects of sochal relnforcement on isolate beha-. vior of a nursery school chila," Behavior Research and Iherapin, 1966, IV, 79-84.

Eandura, A. "Psychotherapy as a Learntng Process," Psychological Eulietin, 19ó1, 58, 143-159.

Banüura, A. Pxinciples of Behavior Modification. New York: Folt, Hinehari, and Winston, Inc.s 1969.

Banciura, A. "Influence of Models" Reinforoenent Contingencies on the Acquisition of Imitative Responses, "Iournel of Personality and Social Psychology, 1965, 1, 589-595.

Bell, J. Q. "Structuring parent-child interaction situations for direct observation," Child Development, 1964, 35, 1011-1020.

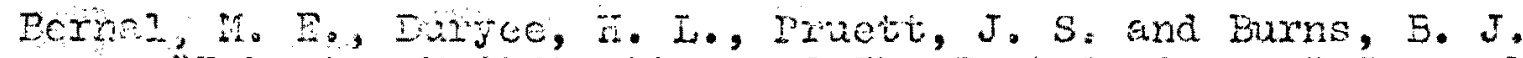
"Behavior Woalificetion and The Bret Syndrome," Journa. of Consult. \& Clinical Esych., 1968, 38, 447-455.

B1jou, S. W. end Baer, D. M. Ch1]d Development. New York: Appleton Century anó Crofts, Inc., 1961, $1, ?$.

Bijou, S. W. "Experimental Studies of child behavlor, normal and deviant," in Krasner, L. and Ullmann, L. P. (eds.) Research in Behavior liodification. New York: Holt, Rinehart, and Winston, Inc., 1965, 56-82.

B1 jou, s. H. Peterson, R. F., Harsis, K. K., Allen, K. E. and Johnston, a. "Kethodolocy for experinental studies of youns children in natural settings," Psycholorical fiecord, 1969, 19, 177-210.

B1rnbrauer, J. S., Bijou, S. W., Wolf, K. M. and Kloder, J. D. "Prozramea linstruction in the classroum," in L. F. UIImann and I. ürasner (eds.), Case Studies in Behavior Modification, New Yonk: Folt, Finehert, and inston, 1955, $358-363$.

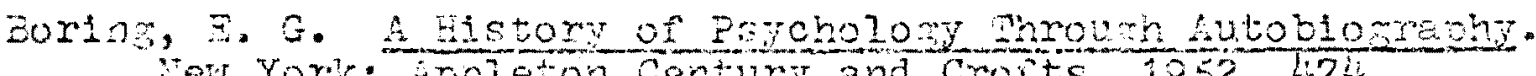
Ten York: Eppleton Century and Crorts, $1952,474$.

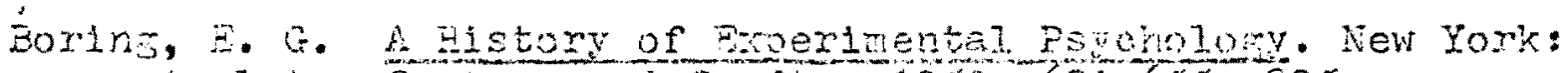
Appleton Century and Crotts, $1950,621-655,395$. 
Breger, L. and McGaugh, J. L. "Critique and Refornulation of Learning Theory Approaches to Psychotherapy," Psycholory Bulletin, $1965,63,338-358$.

Bridgman, P. W. The Logic of Modern Physics. New York: Nacmilian Co., 1927,5 .

Brown, D. G. "Behavior Modification with Chilaren," (Unpublished Manuscript, 1969).

Bucher, B. and Lovaas, 0 . I. "Use of aversive stimulation in behavior modification," In M. R. Jones (eA.), Miami Symposium on the Prediction of Behavior, 1267: Aversive Stimulation. Coral Gables, Florida: University of Miami Press, 1968, 77-1.45.

Byrd, J. "rime Out for Temper Tantrums, " Northwest Magazine, $1969,6-8$.

Cohen, H. I. Filipczak, J. A. and Bis, J. S. "Case Project: Contingencies Applicable for Speciel Education," In Reese, F. P. (ed.), The Analysis of Human Operant Eehavior. Iowa: W. E. Brom Co., 1965, 58-50.

Dittes, J. E. "Galvanio sin responses as a measure of patient's reaction to therapist's permissiveness, "Journal of Abromal and Sucial Psychology, $1957,55,295=$ 303.

Durant, W. The Story of Philosophy. New York: Sinon \& Schuster, 1933, 265-266.

Fairweather, G. W., Sanders, D. H., Maynard, H. and Cressier, D. I. Community Iife For The Hentelly II1: Ar Altexnative to InstitutionaI Care. Chicago: AIdine Co., 1969.

Findiey, J. D. "Programed environments for the experimental analysis of human behavior," In W. K. Honlg (ed.) Coerant Behavior: Areas of pescarch and Aoolication. Fen? York: ippleton Century and Crofts, $1960,827-848$.

Fuller, P. R. "Operant conditioning of a vezetative human organism," In UIlrnann, L. P. and Krasner, L. (ecis.) Case Studies in Eehavior irocification. Tew York: HoIt, Rinehart, arcininston, Ine., $1905,337-339$.

Gelfan, $F$, and jartmann, D. F. "Jehevior Therapy wth ohilaren: A revion and evaluation of research methocology," Esvoholoses Evlletin, 1968, 09, 204-215. 
Geiss, G. I., Stebbins, H. C. and Lundin, R. W. Ireflex and Cperent Conditionins: The Study of Benayior. New York: Appleton Century and Crofts, 1965, I.

Hamblir, E. L., Buckholt, D., Bushell, D., Ellis, D. and Ferritor, D. "Changins the game from "Get the Teacher" to "Learn'" Trans-Action: Social Science and Moderm Society, 1969, Jan., 20-31.

Hanf, D. "Behavior Modjfication as a method for Ivestigating Mother-Child interactions: Part I, Standardization of Frocedure," A peper read to the Western Psychological Association Conference, Warch $29,1968$.

hianf, C. "Wodifying Problem Behaviors in MothermChild Interaction: Fart I, Standardization of Procecure," (UnpubIished Hanuscript, 1969 ).

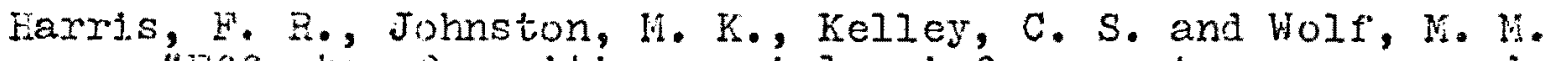
"Iffects or positive social reinfocement on regressed crawing ol a nursery school child," Journal of Educatyonal Fsycholory, 1964, 55, 35-41.

Hawins, R. P., Feterson, I. F., Schweid, E. and B1 jou, S. W. "Behavior Therapy in the Fome: Amerioration of problen parent-child relations with the parent in the therapeutic role," "Tourral of Exoexinental Child Psychology, $1966,4,9 \overline{9-107}$.

Heidbredex, E. Seven Psycholories. New York Appleton Century and Croits, Inc., 1933, 202, 123.

Hirsch, I. and Walden, I. "Training Mothers in groups as reinforcement therapists for the1r own children," A paper presented at the 77 th Annual Convention of the American Psychological Association, 1969.

Folland J. G. and Stinner, B. F. The Analys1s of Behavior. Now York: JeGraw Hill, 1961.

Johnson, J. M. "Using parents as contingency managers," Faper presented to the Annual lieeting of the Southeastern bs johological Association, 1969.

Joves, $A$. C. "The elfmination of children's fears," Journat of Exporjmental PsychoI0ry, 1924, 7, 383-390. AIso in L. D. Ulmen anciraener (ecs.), Fesearch in Eehavior Uodicication. New Yoric: Folt, Jinehart, and WInstion, irce, 1955,261-272.

Krasvar, I. and UIlnann, I. P. Research Ir Behavior Wojifestion. Nev rork: Eolt, Sinehort, anthinstron, Ino., 1965. 
Lindsley, $O$. R. "An experiment with parents handing behavior at home," Jolnstoie Bulletin, 1966, 9, 27-36.

Little, J. C. and James, B. "Abreaction of conditioned fear reaction after eichteen years, "Behavior Pesearch and Iheraoy, $1964,2,59-63$.

Nartin, G. L. and Powers, R. B. "Attention Span: An Operant Conditioning Analysis," Exceptional Chilaren, 1967, 33, $565-570$.

Vowser, O. H. "Learnine theory and behavior therapy," in Wolman, B. (ed.), Mandbook of Clinical Psycholosy. New York: HoGraw Hill, $1965,272$.

Patterson, G. R. and Gulizon, il. S. Living with Children. Illinois: Research Press, 1968.

Patterson, G. R. and Brocisky, G. "A behavior modification programme for a child with multiple problem beheviors," Journal of Child. Psycholosy and Psychiatry, 1967, 7, $277-295$.

Patterson, G. R., Hay, R., and Shaw "Direct intervention in families of doviant children," (Unpublishod Haruscript, University of Orecon, 1968).

Patterson, G. H. and Whtte, G. D. "It's a small world: The application of "tine-out from positive reinforcenent," Neveletter, Oregon Fsychological Assooiation, Feb., 1969.

Peine, H. A. "programing the home," Paper presented at the Amnuaj lieeting of the Rocky Nountain Psychological Association, 1969.

Peterson, R. F. "Expandins the behavior laboratory" From Clinic to Home," Paper presented at the Annual Meeting of the merican Psychological Association, 1967.

Sachan, S. "Ghild Psycholosy and Learning Theory," Joumel $\frac{01}{1962,3}, 3,149-163$.

Heese, $Z$. 2. The Anelysis of Humen onerant Behavior. Iowa: i. c. Exom Co., 1936.

zisieg, 2 . F. "The efiects and sile efrects of punishing the eutietic bonviore of a deviant child," Journel of Ap-

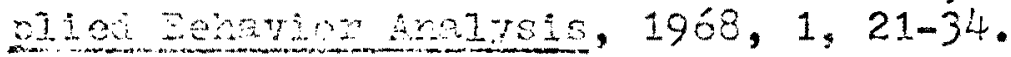

Gusso, 5. "Acaptations tn Eehevioral wheraoy vith Children,"

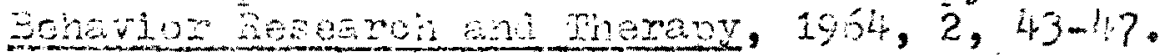


Shah, S. A. "Training and utilizing a mother as the therapist for her child," Paiper presented at the Symposium, Parents as Primary Change Agents in the Treatment of Their Children. April 1967.

Skinner, B. F. Behavior of Organisms. New York: Appleton Cen.tury and crofts, 1938, 6-21.

Skinner, B. F. Autoblogiaphy. In Boring, E. G. History of Psychology in Autobjography. New York: Appleton Century and Crofts, 1952, 386-413.

Skinner, B. F. "Are Theories of Learning Necessary?" Psycho-logical keview, $1950,57,193-216$

Skinner, B. F. "A case history in scientific methodology," American Psychologist, $1956,11,215-233$.

Staats, A. W., Staats, C. K., Schutz, R. E. and Wolf, M. M. "The conditioning on textual responses using 'extrinsic' reinforcers," Journal of the Experimental Analysis of Behav1or, 1962, 5, 33-40.

Straughan, J. H. "Treatment witin child and mother in the playroom," Behavior Research and Therauy, $1.964,2,37-41$.

Tate, B. G. and Baroff, G. S. "Aversive control of selfinjurious behavior in a psychotic boy," Behavior Researoh and Therapy, $1966,4,281-287$.

Ullman, I. P. and Krasner, I. Case Studies in Behavior Modification. New York: Holt, Rinehart, Winston, Inc., 1965, 61.

Valett, R. E. Modifying Children's Behavior: A Guide for Parents and Professionals. Palo Alto: Fearon Publishers, 1969.

wagner, il. K. "Parents therapists: An operant conditionins method," HentaI Fyiene, 1968, 52, 452-455.

Wahler, R. G., Winkel, G. H., Peterson, F. F. and Morrison, D. "Nothers as behavior therapists for their own chiloren," Behavior Fesearch ard Therapy, 1965, 3, 113-124.

Winer, 3. J. Statistical Prinoioles in Experimental Desirn. New York: HeGraw Eil1, $1962,302$.

Wolf, M., Misley, T. and Mees, $̈$. "Application of operant conditioning procenures to the beravior problems of an autistic child," Behavior Research and Therapy,1964, 1, 305-312. 
Wolpe, J. Psychotherapy by Reciprocal Inhibition. Stanford: Stanford University Press, 1958.

Zeilberzer, J., Sampen, S. E. ard Sloane, N. N. "Modification of a child's problem behaviors in the home with the mother as therapist," Journal of Applied Behavior Analysis, $1968,1,47-53$. 


\section{APPENDIX A}

\section{HISTORICAL REVIEW}

Throughout the history of thought, metaphysics had meant an attempt to discover the ultimate nature of reality. With the introduction of Kantian philosophy in Immanuel Kant's Critique of Pure Reason (1781), a book which made its author the leading philosopher of the day, men learned on most respectable authority that "reality could rever be experienced; that it was a 'noumenon' concelvable but not knowable; and that even the subtlest human intelligence could never pass beyond phenomena, could never plerce the vell of Maya." (Durant 1933) Kantian philosophy was a devastating explosion in the traditional modes of speculation and a crippling blast to all metaphysics. By the elghteen thirties, after a generation of metaphysical exuberance expressed by such phllosophers as Fichte, Hegel, and Shelling, with their various readings of the ancient riddle, the1r "Ego", "Idea", and "W1ll", the mind of Europe recovered from "absolute intoxication" and vo.. mited metaphysics. (Durant 1933)

In France, Auguste Conte begen the positivist movement publishing flve volumes of Fositive Fhilosowhy between 1830 and 1842 , and four volunes of Positive polity between 1851 and 1854. For Coxte, phllosophy wes the courcination of all the 
sciences with a social view to improvement of human ilfe. Comte's positivism meant "not speculative nor inferential, but the immediately observeable, the immutable basis of fact Which compels agreement because it is given prior to inference based upon 1t." (Boring 1950) Comte refuted introspection as valid observation, pointing out that "in order to observe your intellect you must pause from activity, and yet, it is this activity you want to observe." (Boring 1950) The positivist movement caught on in England with such well known philosophers as John Stuart Mill, Frederick Harrison, G. H. Lewes, and Henry Maudsley. Ernst Mach (1838-19 $\overline{16})$, also a positivist, disagreed with comte and upheld introspection, claiming that sensations or immediate experience provides all the basic data for science. Mach's positivism was the "reduction of all the phenonena of physics and psycholozy to the immediate data of their observations, to sensations." (Boring 1950)

In 1927, another form of positivism arrived via the Vlenna circle, a group of philosophers among whom were schlick, Carnap, Frank, and Feig]. The purpose of this group was the replacement of philosophy by a systematic investigation of the logic of science. Felsl later ramed this movement "logical positivism" because it reduced all scientific lansuages to the communal languase of piysics, and which in psychology, became "bshavioristics" because the psychological operations are all observations of behavion. (Borins 1950) At the same time the Vierma circle formed, P. W. Bridzmen, a Harvard phy- 
sicist, wrote The Looic of Modem Plysies (1927), a book which attempted to foreso the possiblilty of any major revolution in the attitude of scientists toward nature (such as that generated by Einstein's theories of relativity) by exploiting thoroughly the character of our permanent relations to nature. He tried to clarify physical thinking by stating that concepts in science were to be defired in terms of the operations by which they vere observed. "In general," he wrote, "We mean by any concept nothing nore than a set of operations; the concept is synonymous with the corresponing set of operations." (Bridg$\operatorname{man} 1927$ )

In 1930, Herbert Feigl, a member of the Vienna circle, came to Harvard on a fellowship to work in the philosophy of science. He was knowledgeable of Bridgman's book and quite involved with positivism. Through Feigl, Harvard psychologists became acquainted. With the work of Bridgman, The Vienna circle, and operational procedures in general. B. F. Skinner, then working on his Ph.D. in psychology, got to know the Losic of Hodern Physics and read Poincare and Mach. In 1930, he wrote a thesis on the concept of the reflex adopting the senthistorical method from Hach's Science of Mechanics. (Skinner 1952)

\section{BEXAVIORISH}

It is important to see what events led to the development of Behaviorism in psycholosy. It can be seen that the 
evolution of positivisa in physics and philosophy played a leading role in the development of zeitgeist, and eventually operationism in psychology, but oniy indirectly. Operationism in psychology finds its origin in animal psychology. In Derwin's theory of evolution, the minds of men and anlmals were placed on a continuum, and animal psychology began in England with the publication of "Exoression of Finotions in yen and Animals". (Darwin 1872) Romanes, who followed Darwin coining the term comparative psycholosy, exhibited instances of animal Intelligence and purposive action or "consciousness." Lloyd Morgan squelched the anthropomorphic tenáency of Romanes' interpretation of animal mind by an appeal to the law of parsimony. "In no case may we interpret an action as the outcome of the exercise of a high psychical faculty if it can be interpreted as the outcome of an exercise that stands lower on the psychological scale." (Boring 1952) Jacques Loeb supported Lloyd Morgan, stating his faith in the physico-chemical methods for scientific study of physiology and behavior by advancing the theory of the tropism (1890). He held that associative memory was the only criterior for consciousness and only the lower animals vere therefore "automata" in the Cartesian sense. Herbert Spencer Jennings took Loeb to the simplest organisms and established modiflcation of responses in protozca. Functional psychology at that tame (1900) thought of consciousness as an "organ of man's adaptation and modifiable behavior nade possible by many varjeties of adaptive re- 
sponses." (Boring 1950) Jennings then came to be known as the man who exhibited consciousness in protozoa.

Functional psychology, referred to as the Chicago School, was America's first orfanized stand against the structural school of Wundt and Titchener. It nust be noted that Titchener and Kulpe were adherents to Hachian Positivism, and to them Nach had established the validity of introspection as a scientific method. American functionalism had taken its cue from Darwin and regarded mental processes as useful to the organism adapting to its environment. (Heldbreder, 1933) The functionalists were concerned with the pragmatics of consciousness and opposed the subject matter of psychology set by wund and Titchener as being the description of "experience dependent on an expexiencing person." (Heidbreder 1933)

Behaviorism was the second phase of departure from the structural approach, but in a sense, it was an extrapolation of the Zeitgeist in America. In 1913, John B. Watson founded Behaviorism with a paper entitled, Psychology as a Behaviorist Views It. Watson had taken his Ph.D. at Chicago in the era of functionalism. He could not tolerate the requirement of the Chicago school to transiate positively observed behavior into the vague terms of consciousness. Watson found it more directI.j interesting and positive to study behavior for its own sake. Ile alopted Lloya Horgan's canor of parsimony and amputated consciousness from psycholosy much in tho same way that positivism had exiled metapnysios from philosophy. Watson was the 
agent of a reaction between consciousness through introspection and objectivity in psychology, the result of which was observation of operations in behavior:

Any experimenter who knows fully what went on in his introspective experiment, can transform the data of bchavior, a practice that has been called operationaj reduction, since it substitutes for the purported object of observation the observational operations thenselves. Could that piece of logic coine into knonledge a century earlier, it would have seved a sxea deal of unnecessary talk. (Boring 1950)

Through Watson, Behaviorism became a psychology of stimulus and response as he proceeded to translate mentalistic concepts like imagery, feeling, and association into such behavioral terms as vocimotor behaviox, slandular activity, and Favlovian conditioned reflexes, respectively. Those who followed Watson in the development of behavior principles were Holt, Tolman, Lashley, Velss, Skinner, ani Hull.

\section{B. F. Skinner}

As an undergraduate at Familton College, Skinner majored in English and took a lot of biology. His blology propessor introduced him to Jacques Loeb's Physiology of the Brain and Comparative Dezcholong and later to Pavlov's Conditioned Reflexes. Two years aiter he graduated, skinner was pursuing a Iiterary career at Greenilch Village where he became acquainted with Bertrand Pussell's articles in the Dial magazine on the epistemolosy of John D. Watson's Behaviurism. Fere skinner meie contact with positivisn, as Russell vas extrapolatins the principles or an objective formulation of be- 
havior to the problen of knowledge. Skinner was interested in human behaviox but the literary method had falled him so he turned to science and entered graduate studies in psychology at harvard. He soon came into contact with W. J. Crozier who had studied under Jacques Loeb and was then professor of physlology at Haxvard. As far as skinner was concerred, the fact that Crozier and Loeb talked about aninal behavior without mentioning the nervous system "cancelled out the physiological theorizing of pavlov and sherrington and thus clarified what remained of these two men as the beginnings of an independent science of behevior." (Skinner 1956) As has been mentioned, Skinner became familiar with P. W. Bridgnan's Logic of Modern Physics and read Poincare and Mach. In 1931, he received his Ph.D. following which Crozler gave him a two year fellowship at the subterranean laboratory. He worked in the laboratory for five years, the last three as a Junior Fellow in the Harvard society of Fellows. In his search for order in behavior, Russell and Watson had provided him no glimpse of experimental method but pavlov had "control the environnent and you will see order in behavior." (Skinner 1952) Thus besen Stinner's work on "operant behavior", a term he first used in the Behavior of Orsanisms (1938).

Skinner vent directly to observation of operailons in behavior for his data in forrulatins a systen of behavior. Fe considered researoh vithout comminent to theories as possibly nore conduclve to stujy in new areas and new orders of 
magnitude, and stated that theories which move from the observation of operations in behavior are misleading and imply another dimensional system not contained in the observed behavior. (Skinner 1950) For his terminology, he rejected much of popular vocabulary on the sole criterion that popular terms carry the implication of a system or a formulation which goes beyond immediate observations. By behavior, he simply meant "the movement of an organism or of its parts in a frame of reference provided by the organism itself or by various external objects or fields of force ... the functioning of an organism which is acting on or having commerce with the outside world." (Skinner 1938) In studying behavior, he made a strong point of observins only the correlation between stimulus and response (reflex). The advantage of this approach was seen as obtaining a system of behavior which has a structure determined by the subject matter itself. Skinner describes two types of behavior, "respondent" amd "operant". Much work had been done on respondent behavior since Pavlov's time and it came to be assumed by many vriters that al. vior woulc be accountel for by properly lientisyins the appropriate antecedent eliciting stimuli. But Skinner objected to this assurption saying that there is a laree anount of behavior that does not seen to be 'elicited', since one can observe no correlation between antecedent events anc corresponding responses. To force all behavior trito the stimulus re'sponse formula has delajed the treatment of ths 'other' beha. 
vior. Aidressing himself to this other (operant) behavior, Skinner said that events in behavior can occur without any observeable antecedent events (unconditioned stimuli) and thus the behavior is enltted spontancously rather than elicited. This type of spontaneous behavior he called operant, which refers to a subsequent event, a consequence.

In describing what he meant by operant behavior, Skinner established two laws: 1) The Law of Conaltioning of type $R$ : If the occurrence of an operant is followed by presentation of a reinforcing stimulus, the strength (frequency) of the operant is increased; 2) The Law of Extinction of type $R$ : If the occurrence of an operant already strengthened through conditioning is not followed by the reinforcing stimulus, the strength (frequency) is decreased. (Skinner, 1938) The interaction between an orfanism and the environment describes operant behavior or behavior that is affected by its environmental consequences. 


\section{APPENDIX B}

Pecurrent Situations in Which Mothers' Management of The1r Children Reportealy Breaks Down and the Iaboratory Analoss that Reflect Bach Situation (Nomother, $C=C h i l d, 0=0 t h e r$, $S=S p e c i a l i s t) \quad$ (Reproduced With permission, Harf, 1969)

Expected Problem Situations Feported by Wothers Standainc Situetion Code

1. I can't read a book, watch TV dr sew but what he interferes, wants my attention, or hangs on me.

2. I can't get through to him; he won't mind me. He never does what I ask.

3. a) When we are both together, he won't let anyone else come near us. When they do, he screams.

b) She always hangs on me when someone comes - she even rips iny clothes, she hangs on so t1ehtly

4. a) I can't talk with a nelghbor over a cup of coffee.

i) We never have company anymore, he's such a nuisance.

c) He nags and persists so much whenever someone else is arount.

5. a) I'in going to put him into a day nursery for a few ciays so I can paint a room in the house; he gets into things when I con't watch him.

M occupied, $C$ to play alone

N \& C play together

a) C's gome mules

b) M's fame rules

Clean-up

0 enters room, or

O approaches $C$ while

$M$ is occupied in room

b) I can't let him go out of my sicht; he runs away, he destroys things. 


\section{APPENDIX B}

\begin{tabular}{|c|c|c|}
\hline Eyoected probler situations Reported by Kothers & Standara situation & Cose \\
\hline $\begin{array}{l}\text { Ge vouldn't let the doctor look into his eyes } \\
\text { (nouth, etc.) and it is necessary that we know } \\
\text { wother he's not seeing, } 1 \text { s retarded or whether } \\
\text { he just won't mind. }\end{array}$ & $\begin{array}{l}S \text { examines } C-M \\
\text { in room, or } M \text { leaves }\end{array}$ & $S$ \\
\hline $\begin{array}{l}\text { 7. a) If someone just rings the doorbell she cries } \\
\text { end cries. } \\
\text { b) Le won't let me leave him even for a minute, } \\
\text { even to set a cup of coffee, so, I carry him } \\
\text { ifth me. }\end{array}$ & $\begin{array}{l}\text { M increases physical } \\
\text { distance from C wille } \\
\text { in room } \\
\text { M moves C from lap } \\
\text { to floor. }\end{array}$ & $P$ \\
\hline
\end{tabular}




\section{APPENDIX C}

Codes, Description, and Instructions to M for construction of standard laboratory environments and free-time environment $X$.

\begin{tabular}{|c|c|}
\hline Codie & Description \\
\hline B & $\begin{array}{l}\frac{M}{\mathrm{C}} \text { and } \underline{\mathrm{C}} \text { play } \\
\text { rules }\end{array}$ \\
\hline c & $\begin{array}{l}\frac{M}{M} \text { and } \underset{C}{C} \text { play } \\
\text { rules }\end{array}$ \\
\hline$z$ & Clean up \\
\hline
\end{tabular}

Instructions

You play in whatever game or activity chooses. It is his choice of games and his rules.

Get to play in a game you choose and keep him at this. You can change games but keep him at this. Don't choose games he likes especlally.

Get to put toys wherever you want them (ve cion't care). The idea is to get him to do things you ask him to do.

\section{$\mathrm{X}$ \\ Free-time}

After $M$ had a chance to read the list of instructions presented by the secretary, she would be greeted by $\mathrm{E}$, who would introduce himself as a member of the tean that would be working with her. He would then say, "If you vill come with me to the playroom we will be able to get started shortiy... (on the way to the playruom)... Ve prefer to have you stay down here while we are setting set up with the equipment... (at the playroom door)... It will take us a fev minutes and when we are ready we will jet jou know via the 
APPENDIX C

$\frac{\text { Code }}{x} \frac{\text { Description }}{\text { Free-time }}$

Instructions

wireless communication system. E then fives her the Bus-in-. the-Ear device and closes the door. AII M-C criteria behaviors are recorded for five minutes before the instructions for the next standard laboratory are announced. 


\section{APPENDIX D}

Eight Criteria Behaviors and Their Operational Definitions Observed and Recorded in all Laboratory Environments for all $\underline{N-}-\underline{C}$ pairs.

\section{Rewards}

2. Commands
A) Physical Rewards: Any positive physical contact administered after a particular behavior has occurred. Examples: pats, kisses, hugs, roughs up hair, lifts up in aj. takes C's face in hands

B) Unlabeled Revrards: Nonspecific comments or gestures of liking and approving C's behavior. Examples: "Atta boy," "That's my big boy," "Mommy likes that," "Oh my!" "Wowl" Clapping hands, sin1ling (when $C$ looks at $M$ ) in response to $\overline{\bar{C}}$ 's behavior.

C) Labeled Rewar̂s: M's verbal or physical specification of the exact desirable act or event just performed by $\mathbf{c}$. Examples: "What a good boy for plicking up those blocks." "You sure help momma draw plctures nice." "I like it when you do ..." Gestures, plus pointing directly to what $\mathrm{C}$ did that was liked.

A) Direct Commands: Any specific order, demand, or airection during play or activity that is not in question form. Examples: "Let momma see this" "Roll 1t to momma." "Nol Do not do ..." "Stop thatl" Gestures in the forn of a command, 1.e., points and glowers (C rust be able to see this). 


\section{APPENDIX D}

BERAVIORS OF MOTHERS

2. Commands - continued

3. Follows in C's play

4. G1ves up Control

5. Asks questions
DEFINTTIONS

B) Indirect Commends Any suggestion which cues $C$ to do something or stop döing something in question and/or conditional form. Examples: "Why don't we erase this?" "Maybe we could plck these up." "Woulan't it be nice if we left the room neat?" "How about stopplng that?" "Suppose wedo that later."

$M$ attends to $\underline{C}$ during his play or activity. Examples: $M$ describes or imitates what $\underline{C}$ is doins; M watches what $\underline{C}$ Is cloine and emits verbal or physical cues that she is observing with apparent interest; $N_{1}$ introduces nothing new which would cue $\mathcal{C}$ to change his activity.

II changes activity or does nothing in response to $C^{\prime} s$ noncompliance to her command or suggestion. Examples: $M$ complies to her own commend intended for $\underline{c}$. joes what $C$ suscests as an alternat1va. M pleass or bess $C$ efter his noncompliance. $\frac{\pi}{t}$ states, "Ciray, if you don't want to, jou don th have to." $M_{2}$ does sonethins else after command ama does not attend

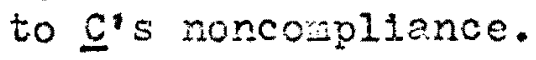

Any latexrogation or susgestion in oucition form. Examples: "vhere a 10 you put 1t?" "Con't you do it?" "What is this?" "Why did you do that?" 
APPENDIX D

\section{Interaction}

7. Independent Play

8. Compizes
C Initiates and plays continuously with $\mathrm{M}$, $1 . e$. , verbal and/or physsical cooperation in task or play. Examples: physical partic1pation and/or verbalization related to common activity. $C$ attends to $M$ and invites her to participate in his game.

c occúpies himself in play or activity. $\subseteq$ does not respond to 1 or others who may comment, describe, command, varn, etc.

C's behavior in response to commands or sugsestions in task or play. C carries out direction of coinnind or suggestions. 